Article

\title{
Computational Scale-Up for Flood Fed/Starve Fed Single Screw Extrusion of Polymers
}

\author{
Andrzej Nastaj (D) and Krzysztof Wilczyński *(D)
}

Faculty of Mechanical and Industrial Engineering, Polymer Processing Department, Warsaw University of Technology, Narbutta 85, 02-524 Warsaw, Poland; a.nastaj@wip.pw.edu.pl

* Correspondence: k.wilczynski@wip.pw.edu.pl

Citation: Nastaj, A.; Wilczyński, K. Computational Scale-Up for Flood Fed/Starve Fed Single Screw

Extrusion of Polymers. Polymers 2022, 14, 240. https://doi.org/10.3390/ polym 14020240

Academic Editor: Keon-Soo Jang

Received: 16 November 2021

Accepted: 5 January 2022

Published: 7 January 2022

Publisher's Note: MDPI stays neutral with regard to jurisdictional claims in published maps and institutional affiliations.

Copyright: () 2022 by the authors Licensee MDPI, Basel, Switzerland. This article is an open access article distributed under the terms and conditions of the Creative Commons Attribution (CC BY) license (https:// creativecommons.org/licenses/by/ $4.0 /)$.

\begin{abstract}
A novel scaling-up computer system for single screw extrusion of polymers has been developed. This system makes it possible to scale-up extrusion process with both starve feeding and flood feeding. Each of the scale-up criteria can be an objective function to be minimized, represented by single values or functional dependencies over the screw length. The basis of scaling-up is process simulation made with the use of the GSEM program (Global Screw Extrusion Model). Scaling-up is performed using the GASES program (Genetic Algorithms Screw Extrusion Scaling) based on Genetic Algorithms. Scaling-up the extrusion process has been performed to increase extrusion output according to the scaling-up criteria defined by the single parameters of unit energy consumption, polymer plasticating rate and polymer temperature, as well as by the process parameters profiles of the temperature and plasticating. The global objective function reached the lowest value for the selected process parameters, and extrusion throughput was significantly increased.
\end{abstract}

Keywords: polymers; extrusion; scale-up; optimization

\section{Introduction}

Computer modeling is widely used for designing polymer processing. However, CAD/CAE systems, while useful, do not make it possible to optimize the process. Extrusion optimization is a complex issue due to the multiplicity of potential optimization criteria, often contradictory, as well as a very large number of process data: material data, geometry, and operation parameters.

Optimization consists in creating a multidimensional response space of process parameters based on input parameters and searching for extreme values in this space, maximum or minimum. Data for optimization can be obtained on the basis of experimental or simulation tests, but optimization based on simulation data is more effective.

There are many different optimization methods which can be classified into: analytical, stochastic, and enumerative [1-10]. A characteristic feature of analytical methods is using the gradient of objective function while searching the optimal solution. These methods can be used when derivatives of the objective function are available and when this function is continuous. Furthermore, the application of these methods is limited to unimodal objective functions. Enumerative methods consist in searching the extremes by browsing successively through all possible points of the finite search space. These methods allow to find a global extremum of the objective function. However, their disadvantage is the huge computational cost in case of multidimensional and complex search spaces. Stochastic methods are completely different class of optimization methods. A characteristic feature of these is the use of random mechanisms for searching the extremes of the objective function. Stochastic methods include: simulated annealing and evolutionary computation. Simulated annealing is a probabilistic technique for approximating the global optimum of a given function. It is often used when the search space is discrete as well as in the cases when finding the approximate global optimum is more important than finding the exact 
local optimum in a fixed time. Evolutionary computations, which are the basic approach of stochastic optimization, consist in searching the extremum of the objective function analogously to the evolution processes in nature and inheritance mechanisms. This is a zeroth-order stochastic method which means that only the values of the objective function are required for searching the extremes. This allows to solve a wide range of optimization tasks where the objective function may be multimodal, discontinuous, non-differential, non-stationary, multivariate, etc. The most widely known evolutionary method are Genetic Algorithms [11-15].

Optimization methods based on Genetic Algorithms are of particular importance in the case of polymer extrusion [16-26].

In general, Genetic Algorithms are characterized by the following features [11]:

- Parameters of the optimization task are processed in the coded form,

- $\quad$ Searching the solution of the optimization task is performed from a randomly selected population, which avoids local extremes,

- The rules of selection of population are probabilistic,

- A new area of searching is determined using previous experiences,

- Only the values of the objective function are required for searching the extremes, the derivatives are not needed.

These methods have been used to optimize most of extrusion processes, i.e., classical flood fed single screw extrusion [16-20], co-rotating extrusion [21-23], and starve fed single screw extrusion [24-26]. There is a lack of optimization studies on counter-rotating extrusion, although the appropriate mathematical models of this process are available [27-29].

An important method of designing physical processes is scaling, i.e., changing the scale of the process according to the selected criteria while maintaining the parameters of the scaled process at a level as close to the parameters of the reference process as possible.

When scaling-up the extrusion process we define the screw geometry and operating conditions of an extruder under designing (the target extruder) that should replicate the operation of the reference extruder. Scaling-up enables to design large extruders based on the studies on the laboratory scale.

Over the years, a number of various scaling-up concepts were proposed. These were discussed in books [30-36] and in a number of papers.

Most scaling-up concepts were based on the analytical models and consisted in correlating the large and small primary scaling parameters (screw diameter, screw length, screw channel depth, and screw rotational speed) in terms of the exponent of the ratio of the target screw diameter and the reference screw diameter

$$
\frac{X_{2}}{X_{1}}=\left(\frac{D_{2}}{D_{1}}\right)^{s}
$$

where $X_{1}, X_{2}$ are the small and large parameter; $D_{1}, D_{2}$ are the small and large screw diameter; $s$ is the scaling-up factor.

Carley and McKelvey [37] were the first to scale-up the extrusion process. They considered the metering section of the screw, and proposed to increase the screw channel depth and width in proportion to the ratio of screw diameters, while maintaining the screw rotational speed constant. Later, several other scaling-up concepts were presented [38-48]. Pearson [42], as the first, performed the full extrusion scaling-up analysis considering the solid transport, polymer plasticating and melt flow. The acceptable scale-up was obtained when the numbers of Graetz, Brinkman, and Nahme were constant in the individual zones of the screw. The advantage of this concept was the balanced solid transport, polymer plasticating, and melt flow, the constant specific power consumption, and the power law dependence of the primary parameters.

Rauwendaal $[30,46]$ analyzed and compared the existing scale-up methods and noticed in most cases the unbalanced solids and melt conveying rates and the excessive viscous dissipation, and confirmed a lack of generality of these methods. 
This analysis was extended by Covas and Cunha [49] who concluded the available scale-up methods:

- $\quad$ Can tackle the single scale-up criteria only, e.g., plasticating rate or pumping rate and the single step of the process, e.g., polymer plasticating or melt flow;

- Can take into account only a few geometry or process parameters, e.g., screw rotational speed, screw diameter, screw channel depth, screw length;

- Use the simple mathematical models;

- $\quad$ Are not flexible.

Thus, the more effective scaling-up methods are needed which would use the accurate mathematical models, and would allow:

- $\quad$ To consider simultaneously several criteria;

- $\quad$ To select the single parameters or functions as the scale-up criteria;

- $\quad$ To freely choose and define the criteria.

Covas and Cunha concluded [49] that these targets can be achieved by considering the scaling-up as a multi-objective optimization, where the aim is to define the geometry/operating parameters of the target extruder in such a way that the performance parameters of both extruders are as close as possible. The scaling-up aim is to minimize the differences between the selected process parameters of the target and reference extruders. The geometry/operating parameters of the reference extruder are known, and these of the target extruder are looked for.

The implementation of these new scale-up concepts requires:

- $\quad$ Simulating the process to have the response data of the reference extruder at a specific set of input data;

- $\quad$ Defining the scale-up criteria;

- $\quad$ Specifing the fixed parameters of the target extruder;

- $\quad$ Performing the scaling-up by minimizing the differences between the selected parameters of the target and reference extruders.

Selection of the scale-up criteria is fundamental for the quality of scaling-up. Usually, the scale-up criteria include the shear rate, the rates of feeding or pumping, the rate of polymer plasticating, the residence time, and the power consumption as proposed by Rauwendaal [46] and Potente [47].

Covas and Cunha [49] proposed additional criteria:

- $\quad$ Ratio of the total/drag flow rate;

- Specific mechanical energy;

- $\quad$ Pressure variation over the unit screw channel;

- $\quad$ Ratio of the screw length required for melting/total screw length (relative melting length);

- $\quad$ Average shear rate;

- Average shear stress;

- Overall vsicous dissipation;

- $\quad$ Average total strain (WATS), which is the measure of mixing degree.

Most of the scale-up criteria are represented by single values but, in some cases, it might have a sense to consider the profiles of them over the screw length. A good example is the solid bed profile (SBP) which is the ratio of the solid bed width to the screw channel width.

Each of the scale-up criteria may be considered as an objective function $F_{i}$ to be minimized, for the single values or functional dependencies, in the form [49]

$$
\begin{gathered}
F_{i}=\frac{\left|C_{i}-C_{i}^{r}\right|}{C_{i}^{r}} \\
F_{i}=\frac{\sum_{k-1}^{K} \frac{\left|C_{i, k}-C_{i, k}^{r}\right|}{C_{i, k}^{r}}}{K}
\end{gathered}
$$


where $F_{i}$ is the $i$-criterion fitness; $C_{i}, C_{i}^{r}$ are the single values of the $i$-criterion for the target extruder and reference extruder; $C_{i, k}, C_{i, k}^{r}$ are the values of the $i$-criterion at the $k$-location over the screw length for the target extruder and reference extruder.

The simple way to do a multi-objective optimization is to take into account the global objective function that includes individual objectives with the use, for example, simple scalar function as was done by Covas and Cunha in optimization of extrusion [16-18,21-23].

Using this approach, Covas and Cunha [49] carried out the scale-up of conventional flood fed single screw extrusion in terms of operating conditions and in terms of screw geometry, as well as they performed the complete scale-up in terms of both operating conditions and screw geometry. This approach allows different criteria to be taken into account at the same time and their relative importance to be considered. The multi-objective scale-up is more efficient than the scale-up based on the single process response because the optimizing procedure finds the solutions that satisfy simultaneously various criteria.

Recently, Vergnes et al. [50] solved the problem of scaling-up the reactive twin screw extrusion, and concluded that the scale-up methods based on the diameter ratios are ineffective as soon as the complex phenomena, like chemical reactions, are involved into the process.

The use of optimization methods for scaling-up, including Multi-Objective Evolutionary Algorithms (MOEA), were also proposed by Covas and Cunha [51-53].

Summarizing, scaling-up the extrusion process based on the process modeling is limited, up to now, to the classical single screw extrusion with flood feeding and to the co-rotating extrusion [49-54]. The state-of-the-art was recently presented in the review paper [55]. Very recently, the authors [56] presented the first approach to scale-up the single screw extrusion with metered feeding, however, it was limited to the process single responses. Counter-rotating extrusion has not been scaled-up, so far.

In this paper, a novel scaling-up computer system for single screw extrusion with both flood feeding and starve feeding is presented. Each of the scale-up criteria can be an objective function to be minimized, represented by single values (Equation (2)) or functional dependencies over the screw length (Equation (3)). The basis of scalingup is the process simulation made with the use of the GSEM program (Global Screw Extrusion Model) [57-59]. Scaling-up is performed using the GASES program (Genetic Algorithms Screw Extrusion Scaling) based on Genetic Algorithms. Examples of scaling-up are presented for both flood fed extrusion and starve fed extrusion to increase the extrusion throughput according to the scale-up criteria defined by the single parameters of unit energy consumption, plasticating rate, and polymer temperature, as well as by the process parameters profiles of temperature and plasticating.

\section{Extrusion with Flood Feeding and Metered Feeding}

Extrusion process can be performed with flood feeding or metered feeding. When flood feeding, the screw is fully filled with polymer (Figure 1a), while when metered feeding, the polymer is supplied into the extruder with a dosing device, and the beginning zone of the screw is partially filled with polymer (Figure $1 b$ ).

Extrusion with metered feeding, also called extrusion with starving, has some advantages over extrusion with flood feeding [30,60-65]. Mixing action is improved, melting is faster, and process control is better. However, the extrusion output is lower.

Single screw extrusion with flood feeding was widely studied, while little studies were performed on extrusion with metered feeding. The state-of-the-art on these issues was discussed in books [30,66-69], as well as in a number of papers [70-75]. Wilczyński et al. reviewed these in [76]. 
a)
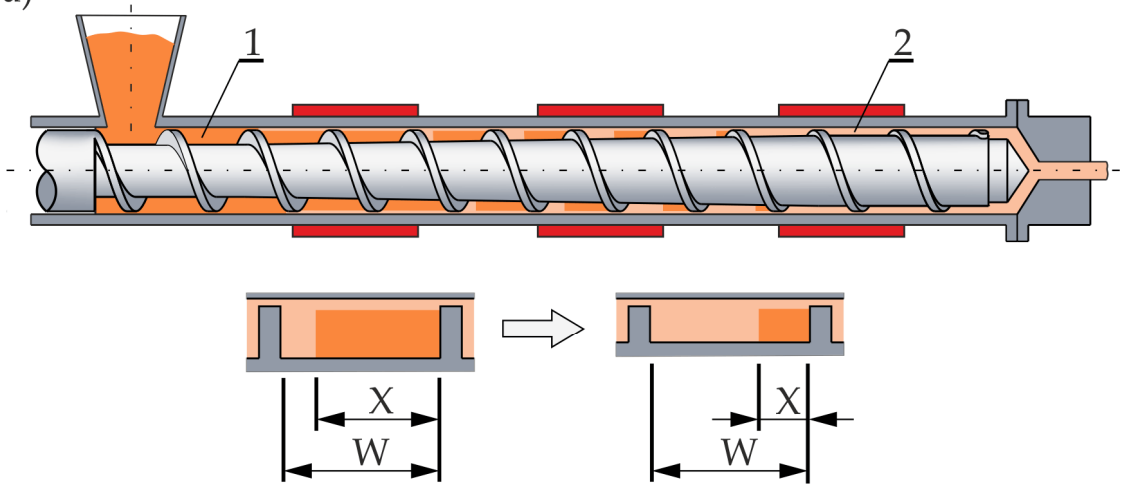

b)
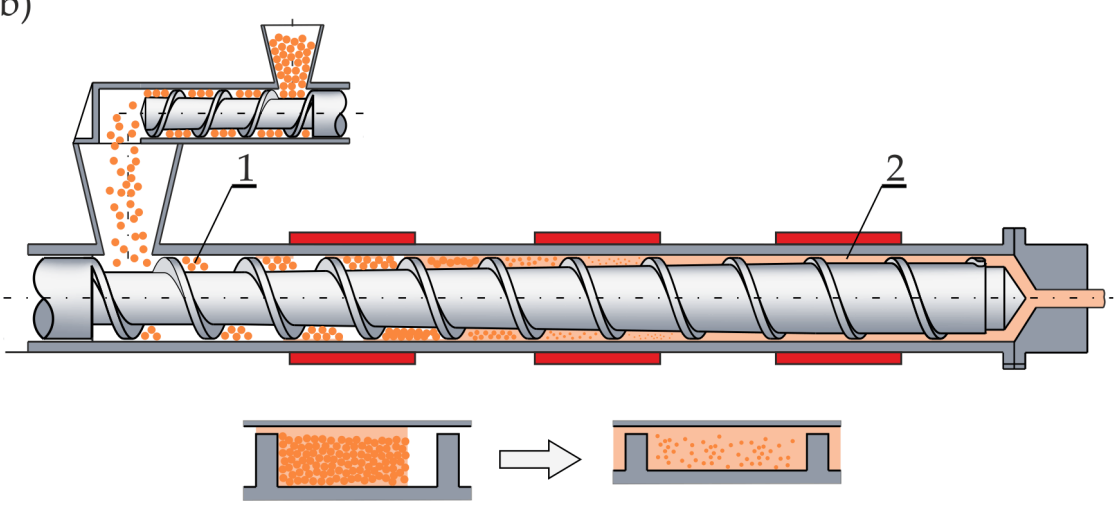

Figure 1. Melting models for single screw extrusion: (a) flood fed extrusion, (b) starve fed extrusion, (1)—solid conveying, (2)—-melt conveying, $X$ —solid bed width, $W$-screw channel width.

Wilczyński et al. made extensive experimental study $[77,78]$, and proposed the plasticating mechanism and model for single screw extrusion with metered feeding, and built the computer model of the process, SSEM-Starve [57]. Two mechanisms of plasticating were observed, plasticating by heat conduction in the partially filled zone of the screw (Figure 1a), and plasticating by energy dissipation in the fully filled zone of the screw (Figure 1b). Later, the models were proposed for non-conventional screws [58,59], and extrusion of polyblends and polymer composites [79-82]. All these models were validated experimentally. Rheology and processing of wood polymer composites were discussed in a review paper [83].

Modeling of starve fed extrusion differs substantially from modeling of flood fed extrusion, and different computation algorithms have to be applied, here. This has been discussed in details in [76].

Computation algorithms for single screw extrusion with flood feeding are well known $[18,84-86]$. The computations proceed forward from the hopper to die, and the process operating point is sought, that is the extrusion output and pressure. Computations start for a presumed flow rate, and solid transport, plasticating, and melt flow are calculated. The computed pressure at the die outlet is compared to atmospheric pressure, and the calculations end when these are equal. Otherwise, the flow rate is changed and calculations are iteratively continued until the convergence is achieved.

Computation algorithms for single screw extrusion with metered feeding are less known [57-59]. The flow rate is known, and the extrusion pressure is calculated for some presumed polymer temperature. Then, the pressure is calculated backward over the screw. When the pressure diminishes to zero, the starvation starts and the filling of the screw is evaluated. The temperature at the plasticating end is compared to the polymer fusion temperature, and calculations end when these are equal. Otherwise, the polymer temperature is changed and calculations are iteratively continued until the convergence is achieved. 
Using these backward algorithms, the models for counter-rotating extruders have been built by the authors [27-29], as have been done by other researchers for co-rotating extruders [87-90]. However, these both models using one-stage melting models are much simpler in execution than the models of starve fed single screw extrusion since the location of melting region is not computed but specified a-priori. In the starve fed single screw extrusion, the location of the transition partially/fully filled screw has to be evaluated in multiple iterative calculations.

Recently, the authors built the program GSEM (Global Screw Extrusion Model) [57-59,91] for simulating extrusion both with flood feeding and metered feeding. Examples of simulations and experimentations are shown in Figures 2 and 3. The process characteristics include the profiles of pressure and temperature, the solid bed profile, and the screw filling profile. It is clearly seen for extrusion with metered feeding (Figure 3 ) that the pressure drops to zero when starvation starts. Two stages of melting are also seen. The partially filled zone and fully filled zone are also seen.

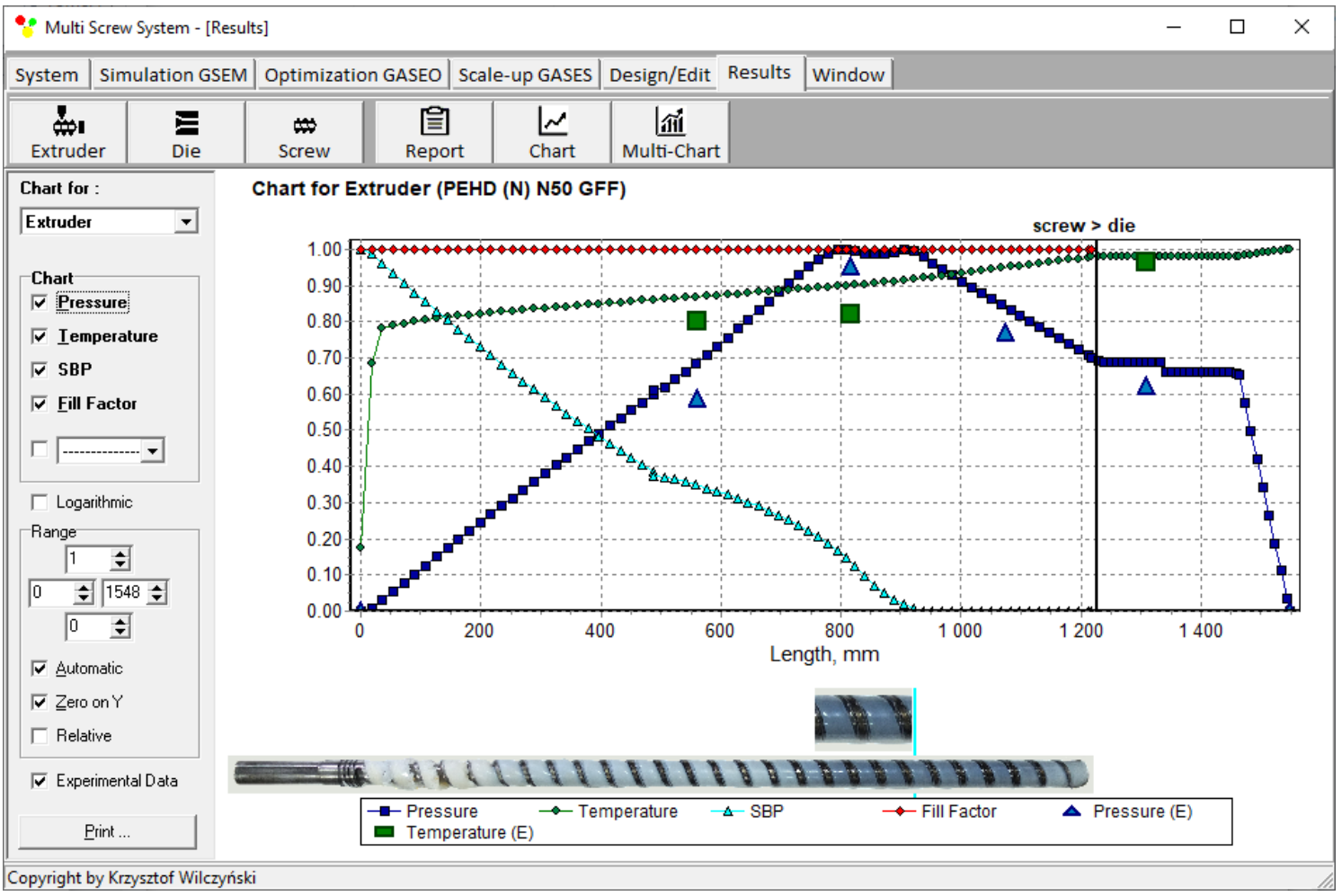

Figure 2. General process characteristics, experiment and simulation with GSEM program-extrusion with flood feeding: $S B P$ —solid bed profile, E-measurements. 


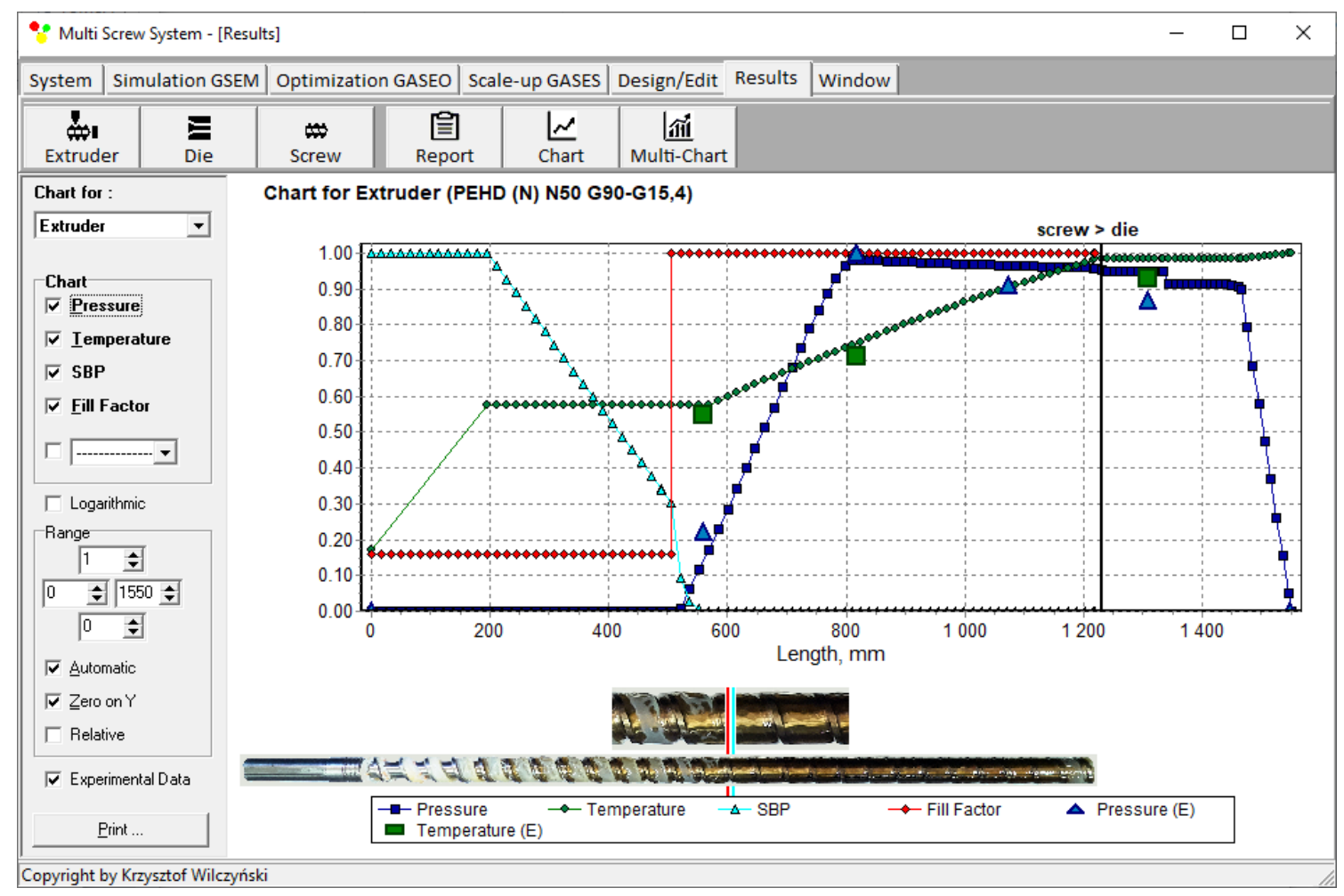

Figure 3. General process characteristics, experiment and simulation with GSEM program-extrusion with metered feeding: $S B P$ —solid bed profile, E-measurements.

\section{Scaling-Up Procedure}

In the study, a scaling-up program GASES (Genetic Algorithms Screw Extrusion Scaling) has been developed. The source of parameters for scaling-up are computations carried out with the program GSEM (Global Screw Extrusion Model) [57-59,91].

GASES scaling-up program, cooperating with the program GSEM, allows for scalingup the extrusion process with various number of process parameters, with various scale-up criteria specified by the single parameters, e.g., specific energy consumption, the rates of solids conveying, plasticating or pumping, as well as by the process parameters profiles, e.g., plasticating profile, temperature profile, etc. The search accuracy of the response surface is determined by the number of divisions of the data range, which results from the length of writing these numbers in binary form. The length of the binary series is regulated, and its maximum length is 255 characters. This makes it possible to divide the range of each parameter into $2^{255}$ values. A "roulette wheel" is applied as a method of selection. An operation scheme of the "roulette wheel" is shown in Figure 4. The area of the "roulette wheel" assigned to the individual genotype is inversely proportional to the values of the objective functions generated by the genotypes. The Ge10 genotype has the lowest value of the objective function $F_{i}=0.9904$, i.e., the highest value of the reciprocal of the objective function $\frac{1}{F_{i}}=1.0097$, and covers the surface of the "roulette wheel" equal to $25.92 \%$ of the total surface of this. The Ge2 genotype has the highest value of the objective function $F_{i}=8.9431$, i.e., the lowest value of the reciprocal of the objective function $\frac{1}{F_{i}}=0.1144$ covering the surface equal to $2.94 \%$ of the total surface of the "roulette wheel".

In the GASES program, scaling-up is defined by the number of scaling variables, the size of initial population, the length of chromosomes, the probability of crossover, the point of crossover, and the probability of mutation. We have not studied the influence of the GA parameters on the results. However, we observed that this influence is rather not important. We observed that GA parameters affect the computation time. We established these parameters based on the literature [11] and our experiences [25,26]. Different weights 
of the criteria are not available. Scaling-up can be performed for extrusion both with flood feeding and metered feeding. This is depicted in Figure 5.

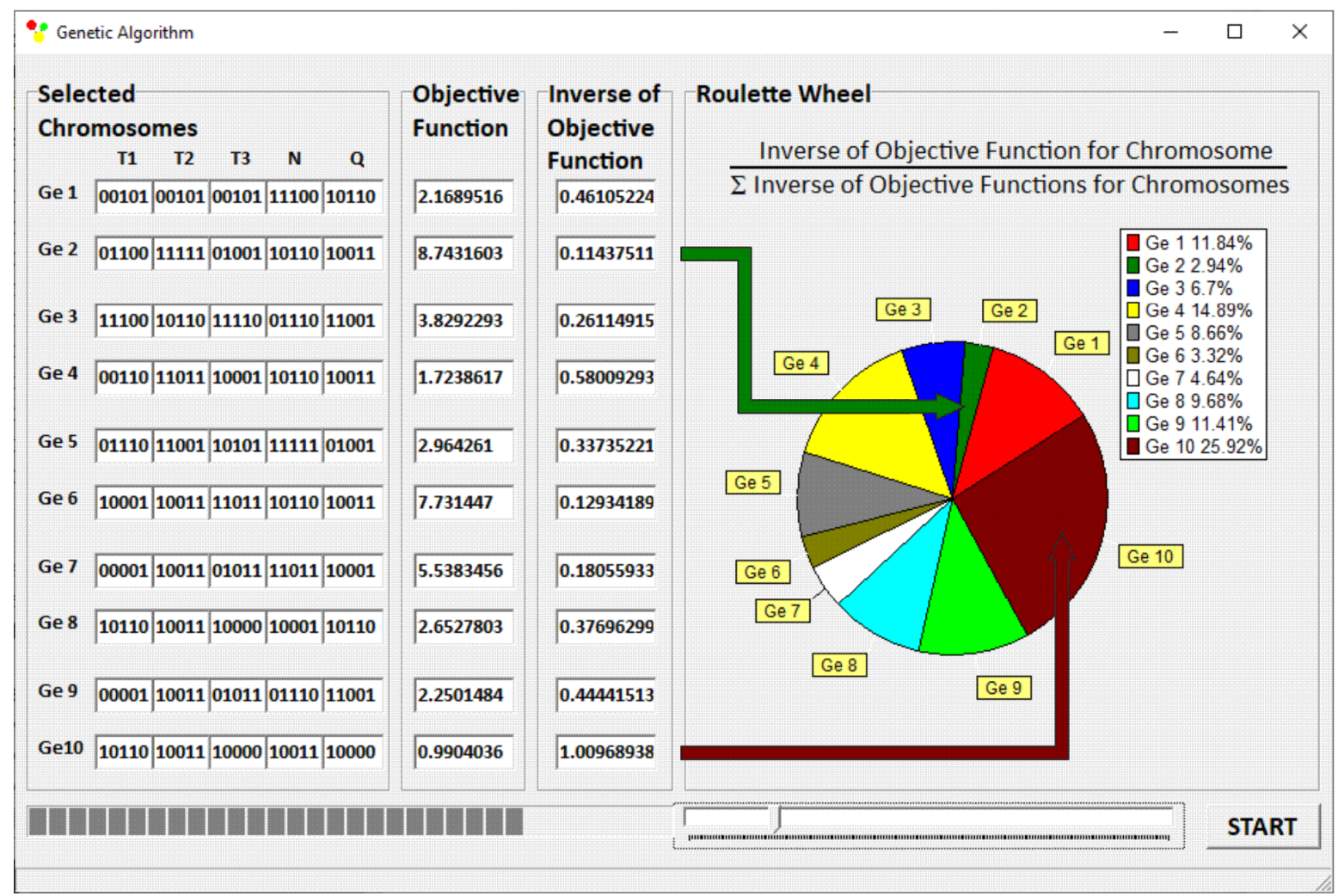

Figure 4. Selection of the initial population and estimation of chromosomes.

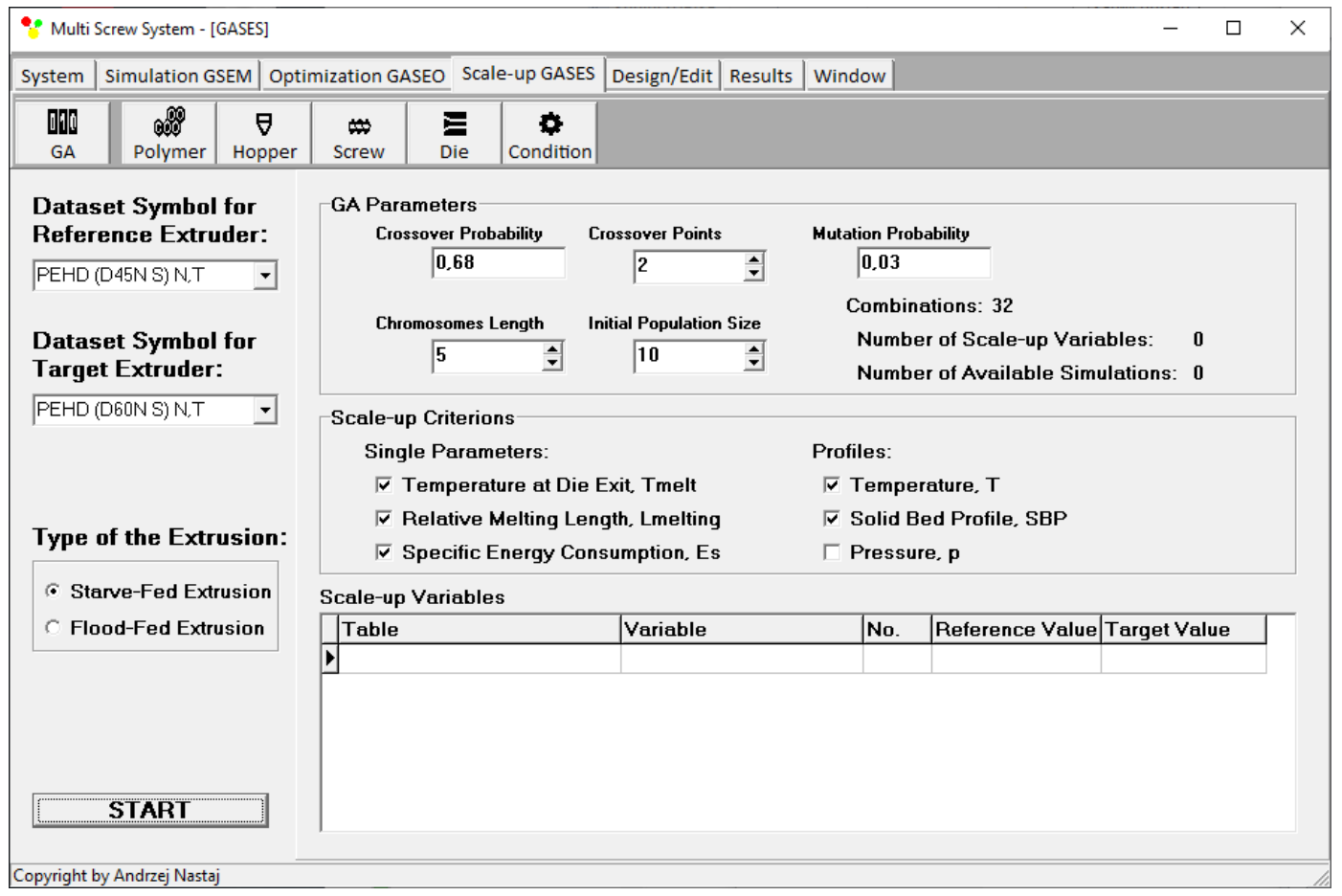

Figure 5. Parameters of the scaling-up procedure. 


\section{Scaling-Up}

\subsection{Research Program}

Scaling-up was made for single screw extrusion to increase the process output according to the scale-up criteria defined by the single parameters of unit energy consumption, polymer melting rate, and polymer melt temperature, and by the process parameters profiles of temperature and melting.

The research program included a scale-up of the extrusion process from the level of the reference extruder with the screw of diameter $D_{r}=45 \mathrm{~mm}$ to the level of the target extruder with the screw of diameter $D_{t}=60 \mathrm{~mm}$ while maintaining the ratio of the length/screw $\left(\mathrm{L}_{\mathrm{r}} / \mathrm{D}_{\mathrm{r}}\right)=\left(\mathrm{L}_{\mathrm{t}} / \mathrm{D}_{\mathrm{t}}\right)=$ constant. The extrusion with flood feeding and metered feeding were investigated.

A classical three-zone screw of diameter $D_{r}=45 \mathrm{~mm}$, and length/diameter ratio $\left(\mathrm{L}_{\mathrm{r}} / \mathrm{D}_{\mathrm{r}}\right)=27$ was applied as a reference screw configuration. It has zones of feeding $(\mathrm{F})$, compression $(\mathrm{C})$, and metering $(\mathrm{M})$ with length/diameter ratios equal to $(\mathrm{L} / \mathrm{D})_{\mathrm{F}}=10.78$, $(\mathrm{L} / \mathrm{D})_{\mathrm{C}}=7.11$, and $(\mathrm{L} / \mathrm{D})_{\mathrm{M}}=9.11$. The compression ratio, that is the ratio of the channel depth $\left(\mathrm{H}_{\mathrm{F}}\right)$ in the feeding zone to the channel depth in the metering zone $\left(\mathrm{H}_{\mathrm{M}}\right)$, $\mathrm{CR}=\mathrm{H}_{\mathrm{F}} / \mathrm{H}_{\mathrm{M}}$, was equal to $\mathrm{CR}=2.66\left(\mathrm{H}_{\mathrm{F}}=8 \mathrm{~mm}, \mathrm{H}_{\mathrm{M}}=3 \mathrm{~mm}\right)$. The die for extrusion of rods of diameter $D_{\text {die }}=5 \mathrm{~mm}$ was used. Screw geometry of the reference and target extruder are presented in Table 1.

Table 1. Screw geometry.

\begin{tabular}{lcc}
\hline & Screw Geometry & \\
\hline & Reference & Target \\
\hline $\begin{array}{l}\text { Length of } \\
\text { feeding/compression/metering zone }\end{array}$ & $10.78 ; 7.11 ; 9.11$ turns & $10.78 ; 7.11 ; 9.11$ turns \\
$\begin{array}{l}\text { Diameter of barrel, } \mathrm{D}_{\mathrm{b}} \\
\text { Screw pitch }\end{array}$ & $45 \mathrm{~mm}$ & $60 \mathrm{~mm}$ \\
$\begin{array}{l}\text { Depth of screw channel in feeding } \\
\text { zone, } \mathrm{H}_{\mathrm{F}}\end{array}$ & $45 \mathrm{~mm}$ & $60 \mathrm{~mm}$ \\
$\begin{array}{l}\text { Depth of screw channel in metering } \\
\text { zone, } \mathrm{H}_{\mathrm{M}}\end{array}$ & $8 \mathrm{~mm}$ & $12 \mathrm{~mm}$ \\
Flight width & $3 \mathrm{~mm}$ & $4.5 \mathrm{~mm}$ \\
\hline
\end{tabular}

High density polyethylene (HDPE) Rigidex 6070EA (manufactured by BP Chemicals) was used in the study. Material properties are presented in Table 2.

Table 2. Material properties-HDPE Rigidex 6070EA.

\begin{tabular}{lc}
\hline \multicolumn{2}{c}{ Material Properties } \\
\hline Density_bulk & $595 \mathrm{~kg} / \mathrm{m}^{3}$ \\
Density—solid & $951 \mathrm{~kg} / \mathrm{m}^{3}$ \\
Density_-melt & $721 \mathrm{~kg} / \mathrm{m}^{3}$ \\
Polymer-barrel friction factor & 0.40 \\
Polymer-screw friction factor & 0.25 \\
Heat of fusion & $245,000 \mathrm{~J} / \mathrm{kg}$ \\
Solid specific heat & $2250 \mathrm{~J} \mathrm{~kg}^{-1} \mathrm{deg}^{-1}$ \\
Melt specific heat & $3000 \mathrm{~J} \mathrm{~kg}^{-1} \mathrm{deg}^{-1}$ \\
Thermal conductivity & $0.27 \mathrm{~W} \mathrm{~m}^{-1} \mathrm{deg}^{-1}$ \\
Melt flow rate $\left(190^{\circ} \mathrm{C}, 2.16 \mathrm{~kg}\right)$ & $7.6 \mathrm{~g} / 10 \mathrm{~min}^{2}$ \\
\hline
\end{tabular}

Rheological properties of the polymer (HDPE) were determined with the use of the high-pressure capillary rheometer RG-25 (Göttfert, Buchen, Germany) at temperatures: $180^{\circ} \mathrm{C}, 190^{\circ} \mathrm{C}$, and $200{ }^{\circ} \mathrm{C}$. The model of Klein was used to describe the viscosity as a function of temperature and shear rate. 


$$
\ln \eta=A_{0}+A_{1} \ln \dot{\gamma}+A_{11} \ln ^{2} \dot{\gamma}+A_{12} T \ln ^{2} \dot{\gamma}+A_{2} T+A_{22} T^{2}
$$

where $\eta$ is viscosity, $\dot{\gamma}$ is shear rate, $T$ is temperature, $A_{0}, A_{1}, A_{11}, A_{12}, A_{2}, A_{22}$ are parameters of the Klein equation, $A_{0}=10.9183, A_{1}=-0.2184, A_{11}=-0.0368, A_{12}=0.0010, A_{2}=-0.0226$, $A_{22}=0.000021$.

\subsection{Scale-Up of Flood Fed Extrusion}

Scaling-up was performed with reference to the extrusion process, the operation parameters of which were determined as a result of optimization. These parameters were screw rotational speed and barrel temperatures. The optimization of the reference process was carried out according to the criteria of maximum throughput $Q_{\max }$, minimum unit energy consumption $E_{S \text { min }}$, and minimum polymer melt temperature at the die outlet $T_{\text {melt }}$ min, in the range of the screw rotational speed $N=20 \div 80 \mathrm{rpm}$ and the barrel temperature in the subsequent sections of the extruder: $T_{1}=150{ }^{\circ} \mathrm{C}, \mathrm{T}_{2}=150 \div 240{ }^{\circ} \mathrm{C}, \mathrm{T}_{3}=150 \div 240{ }^{\circ} \mathrm{C}$, $T_{4}=150 \div 240{ }^{\circ} \mathrm{C}$.

The global objective function was defined as,

$$
F_{i o}=\sqrt[3]{Q_{i \_n o r m} \cdot E_{\text {S i_norm }} \cdot T_{\text {melt i_norm }}}
$$

The output variables (optimization criteria) were normalized as,

$$
\begin{gathered}
Q_{i_{-} \text {norm }}=\frac{Q_{i}-Q_{\text {min }}}{Q_{\text {max }}-Q_{\text {min }}} \\
E_{S_{\text {i_norm }}}=\frac{E_{j i}-E_{j \text { min }}}{E_{j \text { max }}-E_{j \text { min }}} \\
T_{\text {melt i_norm }}=\frac{T_{\text {melt } i}-T_{\text {melt min }}}{T_{\text {melt max }}-T_{\text {melt min }}}
\end{gathered}
$$

where $F_{i}$ o is a global objective function, $Q_{i \_n o r m}$ is a normalized flow rate, $E_{s i \_n o r m}$ is a normalized specific energy consumption, $T_{\text {melt } i \text { norm }}$ is a normalized melt temperature at die outlet, $i$ is a number of the next value from the data set.

The highest value of an objective function was obtained at the screw rotational speed $N=79.53 \mathrm{rpm}$ and the barrel temperatures: $T_{1}=150{ }^{\circ} \mathrm{C}, \mathrm{T}_{2}=192.51{ }^{\circ} \mathrm{C}, \mathrm{T}_{3}=180.47{ }^{\circ} \mathrm{C}$, $T_{4}=180.47^{\circ} \mathrm{C}$. These optimal parameters, according to the assumed optimization criteria of maximum throughput, minimum unit energy consumption, and minimum polymer melt temperature at the die outlet, correspond to the process output parameters of mass flow rate $Q=27.10 \mathrm{~kg} / \mathrm{h}$, unit energy consumption: $E_{S}=489.36 \mathrm{~kJ} / \mathrm{kg}$, polymer temperature $T_{\text {melt }}=254.88^{\circ} \mathrm{C}$, and the relative "melting length" $L_{\text {melting }}=0.796$, i.e., the ratio of the screw length necessary for melting of polymer to the total screw length.

Simulations for the reference extruder at the optimal operation parameters are presented in Figure 6 as a dimensionless process characteristics which includes the profiles of pressure and temperature, the solid bed profile $(S B P)$, and the profile of screw filling (FF).

With regard to such an optimized reference process, the extrusion scaling-up was performed in the same range of input data of the screw speed $N=20 \div 80 \mathrm{rpm}$, and the barrel temperature in the subsequent sections of the extruder: $T_{1}=150{ }^{\circ} \mathrm{C}, \mathrm{T}_{2}=150 \div 240{ }^{\circ} \mathrm{C}$, $T_{3}=150 \div 240{ }^{\circ} \mathrm{C}, \mathrm{T}_{4}=150 \div 240{ }^{\circ} \mathrm{C}$.

Scaling-up was carried out according to the single-parameter criteria of the unit energy consumption $E_{\mathrm{S}}$, the polymer melt temperature $T_{\text {melt }}$, and the relative "melting length" $L_{\text {melting, }}$ i.e., the ratio of the screw length necessary for polymer melting to the screw length, and to the functional criteria of the temperature profile and the plasticating profile, i.e., the solid bed profile $(S B P)$.

The global objective function was defined as, 


$$
F_{i s}=\left|1-\frac{E_{S A}}{E_{S B_{i}}}\right|+\left|1-\frac{T_{\text {melt }_{A}}}{T_{\text {melt } B_{i}}}\right|+\left|1-\frac{L_{\text {melting } A}}{L_{\text {melting } B_{i}}}\right|+\frac{\sum_{k=1}^{n}\left|1-\frac{T_{A k}}{T_{B} i k}\right|}{n}+\frac{\sum_{k=1}^{n}\left|1-\frac{S B P_{A k}}{S B P_{B i k}}\right|}{n}
$$

where $F_{i s}$ is the global objective function for scale-up, $E_{S A}$ is the specific energy consumption for reference extruder, $E_{S B i}$ is the specific energy consumption for target extruder, $T_{\text {melt } A}$ is the melt temperature at die outlet for reference extruder, $T_{\text {melt } B i}$ is the melt temperature at die outlet for target extruder, $L_{\text {melting } A}$ is the relative melting length for reference extruder, $L_{\text {melting } B i}$ is the relative melting length for target extruder, $T_{A}$ is the melt temperature in reference extruder, $T_{B} i$ is the melt temperature in target extruder, $S B P_{A}$ is the polymer melting profile for reference extruder, $S B P_{B i}$ is the polymer melting profile for target extruder, $i$ is a number of the next value from the data set, $n$ is a number of the next value in the profile.

The results of scaling-up are presented in Table 3, and Figures 7 and 8. The lowest value of the objective function (Equation (9)), i.e., the minimum discrepancy between the variables of the reference and target process, was obtained at the screw speed $N=57.14 \mathrm{rpm}$ for the barrel temperatures: $T_{1}=150{ }^{\circ} \mathrm{C}, \mathrm{T}_{2}=200{ }^{\circ} \mathrm{C}, T_{3}=197.85^{\circ} \mathrm{C}, \mathrm{T}_{4}=190.71{ }^{\circ} \mathrm{C}$. These parameters correspond to the process output parameters of the flow rate $Q=44.20 \mathrm{~kg} / \mathrm{h}$, the unit energy consumption $E_{\mathrm{s}}=457.76 \mathrm{~kJ} / \mathrm{kg}$, the polymer melt temperature $T_{\text {melt }}=254.93{ }^{\circ} \mathrm{C}$, and the relative "melting length" $L_{\text {melting }}=0.793$. The differences between the parameters of the reference process and the target process are small (Table 3). Thus, it can be concluded that these processes are similar in terms of the selected criteria. The profiles of temperature and melting are also similar which is clearly presented in Table 3 and Figures 7 and 8 . By increasing the scale of the process, a significant increase in the extrusion throughput was obtained $(63.10 \%)$.

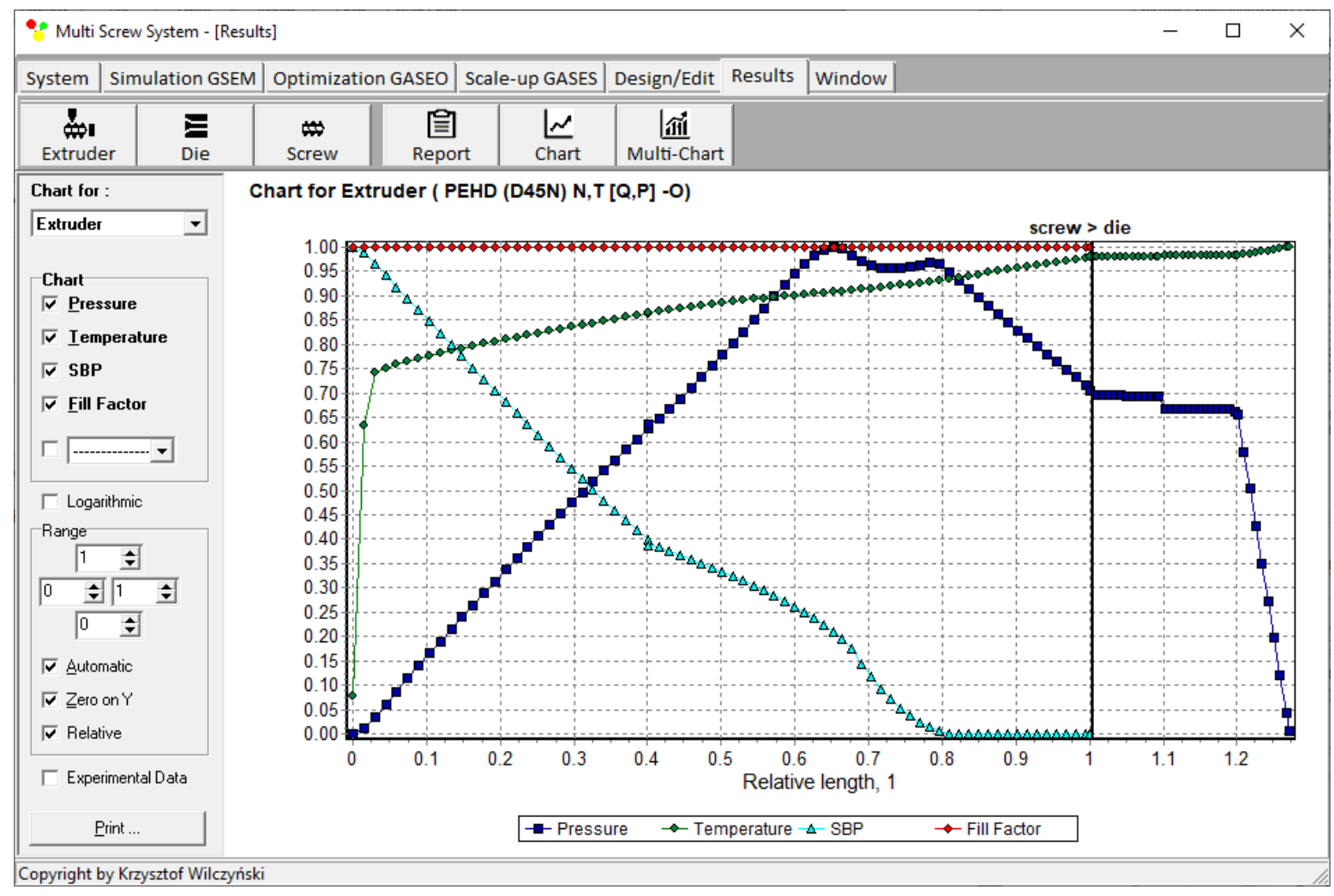

Figure 6. Extrusion with flood feeding: process characteristics (reference extruder) at optimal parameters. 
Table 3. Results of scaling-up the flood fed extrusion process.

\begin{tabular}{|c|c|c|c|}
\hline \multicolumn{4}{|c|}{ Results of Scaling-Up the Extrusion Process } \\
\hline \multicolumn{4}{|c|}{ Extruder } \\
\hline Single Parameter & Reference & Target & Deviation \\
\hline Specific energy consumption & $489.36 \mathrm{~kJ} / \mathrm{kg}$ & $457.76 \mathrm{~kJ} / \mathrm{kg}$ & $6.46 \%$ \\
\hline Relative melting length & 0.769 & 0.793 & $3.12 \%$ \\
\hline Polymer melt temperature & $254.88^{\circ} \mathrm{C}$ & $254.93{ }^{\circ} \mathrm{C}$ & $0.02 \%$ \\
\hline Extrusion throughput & $27.10 \mathrm{~kg} / \mathrm{h}$ & $44.20 \mathrm{~kg} / \mathrm{h}$ & $63.10 \%$ \\
\hline \multicolumn{4}{|l|}{ Profile } \\
\hline \multicolumn{4}{|l|}{ Temperature profile } \\
\hline 1. & $20.00{ }^{\circ} \mathrm{C}$ & $20.00^{\circ} \mathrm{C}$ & $0.00 \%$ \\
\hline 2. & $128.55^{\circ} \mathrm{C}$ & $159.16^{\circ} \mathrm{C}$ & $21.48 \%$ \\
\hline 3. & $176.15^{\circ} \mathrm{C}$ & $184.41^{\circ} \mathrm{C}$ & $4.69 \%$ \\
\hline$\ldots$ & $254.48^{\circ} \mathrm{C}$ & $254.21^{\circ} \mathrm{C}$ & $\begin{array}{c}\cdots \\
0.11 \%\end{array}$ \\
\hline 142. & $254.84{ }^{\circ} \mathrm{C}$ & $254.82{ }^{\circ} \mathrm{C}$ & $0.00 \%$ \\
\hline \multicolumn{4}{|l|}{$S B P$ profile } \\
\hline 1. & 1.00 & 1.00 & $0.00 \%$ \\
\hline 2. & 0.99 & 0.99 & $0.00 \%$ \\
\hline 3. & 0.96 & 0.97 & $1.04 \%$ \\
\hline$\ldots$ & $\ldots$ & $\ldots$ & $\ldots$ \\
\hline 75. & 0.01 & 0.01 & $0.00 \%$ \\
\hline 76. & 0.00 & 0.00 & - \\
\hline
\end{tabular}

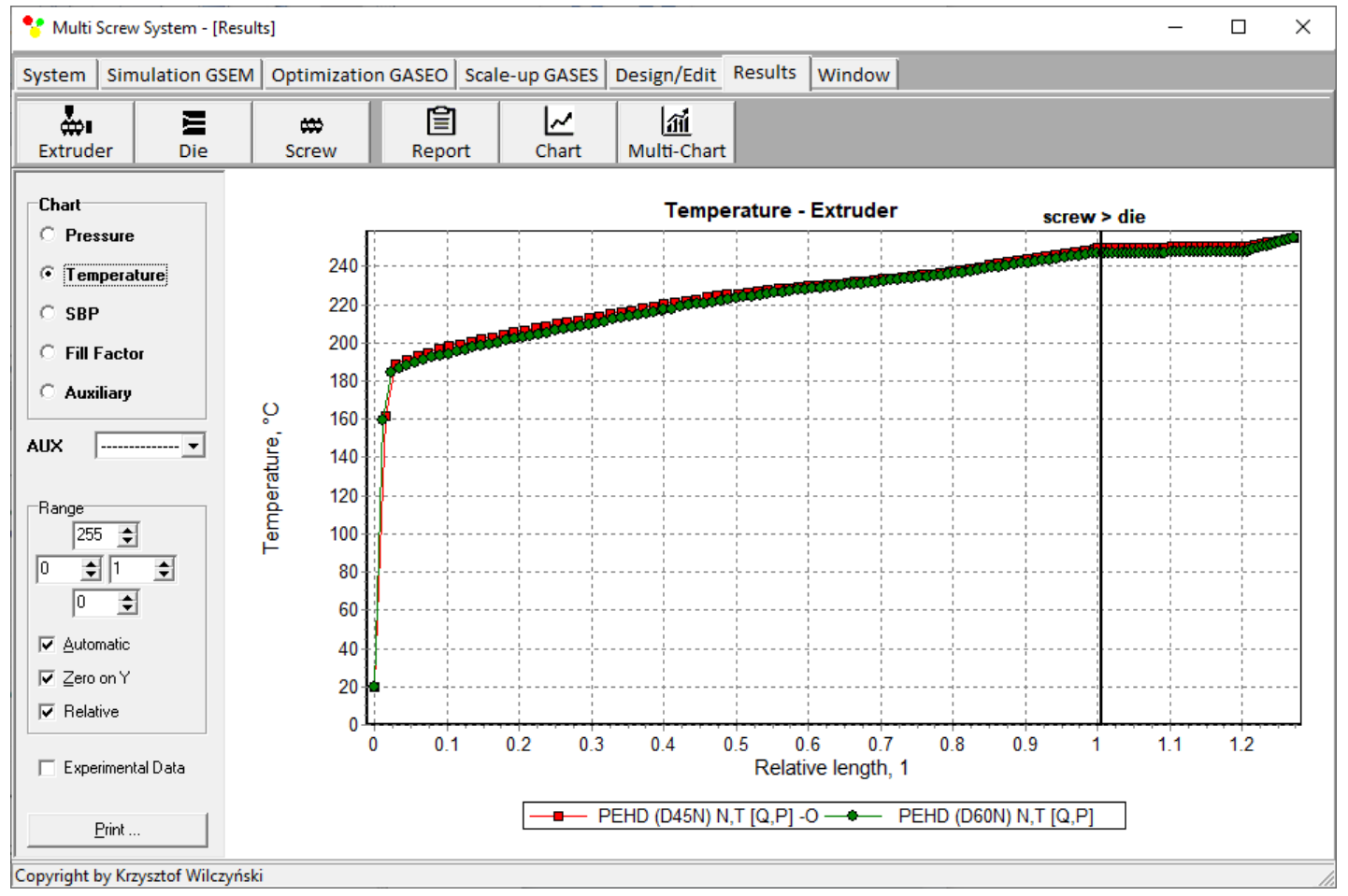

Figure 7. Flood fed extrusion: temperature profile for the reference (red line) and target (green line) extruder. 


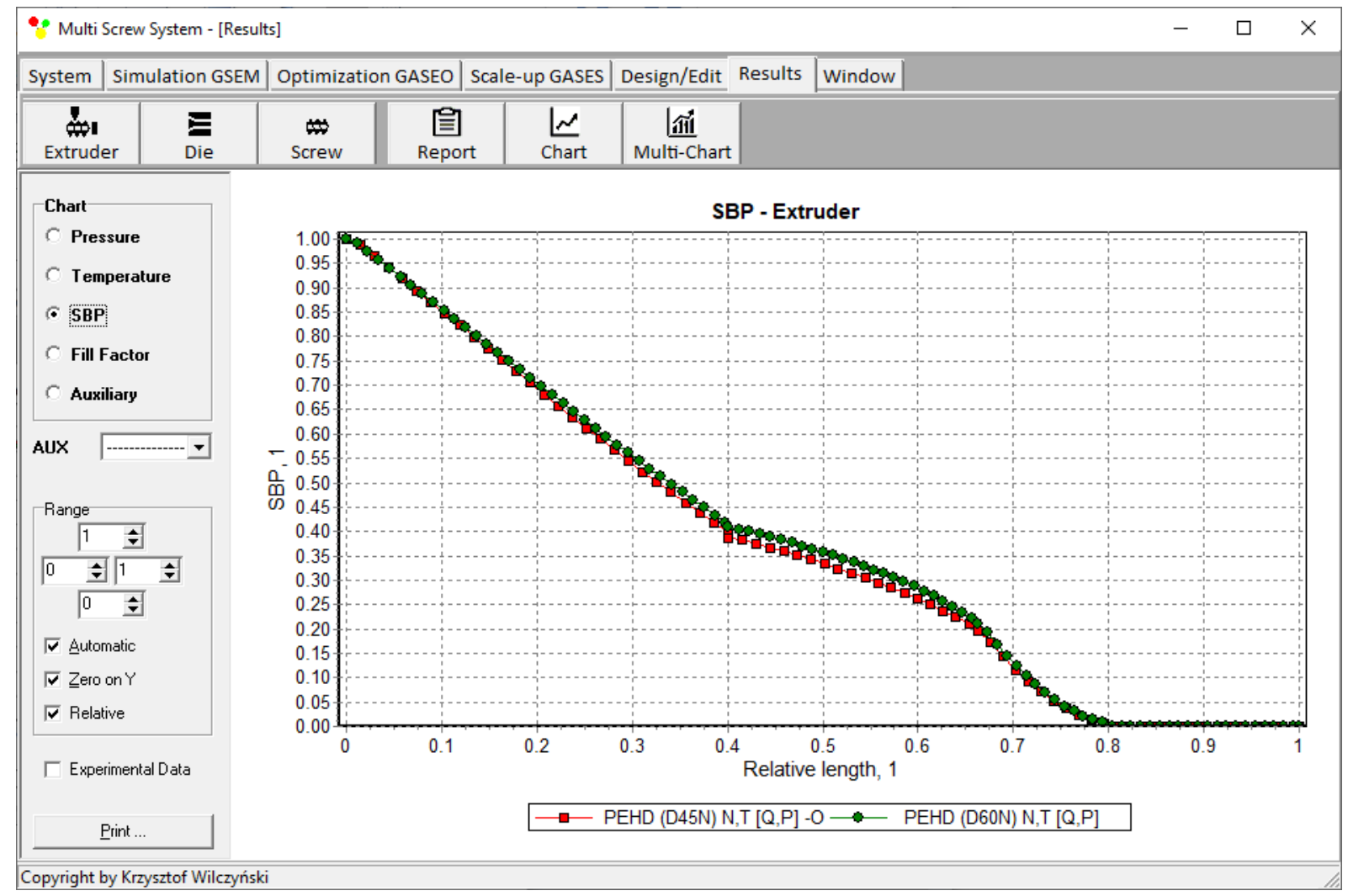

Figure 8. Flood fed extrusion: melting profile $(S B P)$ for the reference (red line) and target (green line) extruder.

\subsection{Scale-Up of Starve Fed Extrusion}

Scaling-up was performed with reference to the extrusion process, the operation parameters of which were determined as a result of optimization. These parameters were screw rotational speed and barrel temperatures. The optimization of the reference process was carried out according to the criteria of maximum throughput $Q_{S T \text { max }}$, minimum unit energy consumption $E_{S} S T$ min, and minimum polymer melt temperature at the die outlet $T_{\text {melt } S T \text { min. }}$, in the range of the screw rotational speed $N=20 \div 80 \mathrm{rpm}$, the barrel temperature in the subsequent sections of the extruder: $T_{1}=150{ }^{\circ} \mathrm{C}, T_{2}=150 \div 240{ }^{\circ} \mathrm{C}$, $T_{3}=150 \div 240{ }^{\circ} \mathrm{C}, T_{4}=150 \div 240{ }^{\circ} \mathrm{C}$, and the feeding rate $Q_{\mathrm{ST}}=27.0 \div 31.5 \mathrm{~kg} / \mathrm{h}$.

The global objective function was defined as,

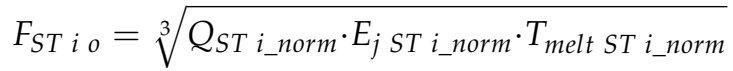

The output variables (optimization criteria) were normalized as,

$$
\begin{aligned}
Q_{S T \text { i_norm }} & =\frac{Q_{S T ~}-Q_{S T \text { min }}}{Q_{S T \text { max }}-Q_{S T \text { min }}} \\
E_{S} S T \text { i_norm } & =\frac{E_{S S T i}-E_{S S T \text { min }}}{E_{S S T \text { max }}-E_{S S T \text { min }}} \\
T_{\text {melt ST i_norm }} & =\frac{T_{\text {melt } S T i}-T_{\text {melt } S T \text { min }}}{T_{\text {melt } S T \text { max }}-T_{\text {melt } S T \text { min }}}
\end{aligned}
$$

where $F_{i_{0}}$ is a global objective function, $Q_{S T} i_{n}$ norm is a normalized flow rate, $E_{S} S T i_{-} n o r m$ is a normalized specific energy consumption, $T_{\text {melt }} S T i_{\_}$norm is a normalized melt temperature at die outlet, $i$ is a number of the next value from the data set.

The highest value of the objective function was obtained at the screw rotational speed $N=80 \mathrm{rpm}$ and the barrel temperatures: $\mathrm{T}_{1}=150{ }^{\circ} \mathrm{C}, \mathrm{T}_{2}=234.33^{\circ} \mathrm{C}, \mathrm{T}_{3}=228.66{ }^{\circ} \mathrm{C}$, 
$T_{4}=222.99^{\circ} \mathrm{C}$, and the feeding rate $Q_{S T}=27.32 \mathrm{~kg} / \mathrm{h}$. These optimal parameters, according to the assumed optimization criteria of maximum throughput, minimum unit energy consumption, and minimum polymer melt temperature at the die outlet, correspond to the process output parameters of mass flow rate $Q_{S T}=27.32 \mathrm{~kg} / \mathrm{h}$, unit energy consumption $E_{S S T}=453.84 \mathrm{~kJ} / \mathrm{kg}$, polymer temperature $T_{\text {melt } S T}=223.31{ }^{\circ} \mathrm{C}$, and the relative "melting length" $L_{\text {melting }}=0.617$, i.e., the ratio of the screw length necessary for melting of polymer to the total screw length.

Simulations for the reference extruder at the optimal operation parameters are presented in Figure 9 as a dimensionless process characteristics which includes the profiles of pressure and temperature, the solid bed profile (SBP), and the profile of screw filling (FF).

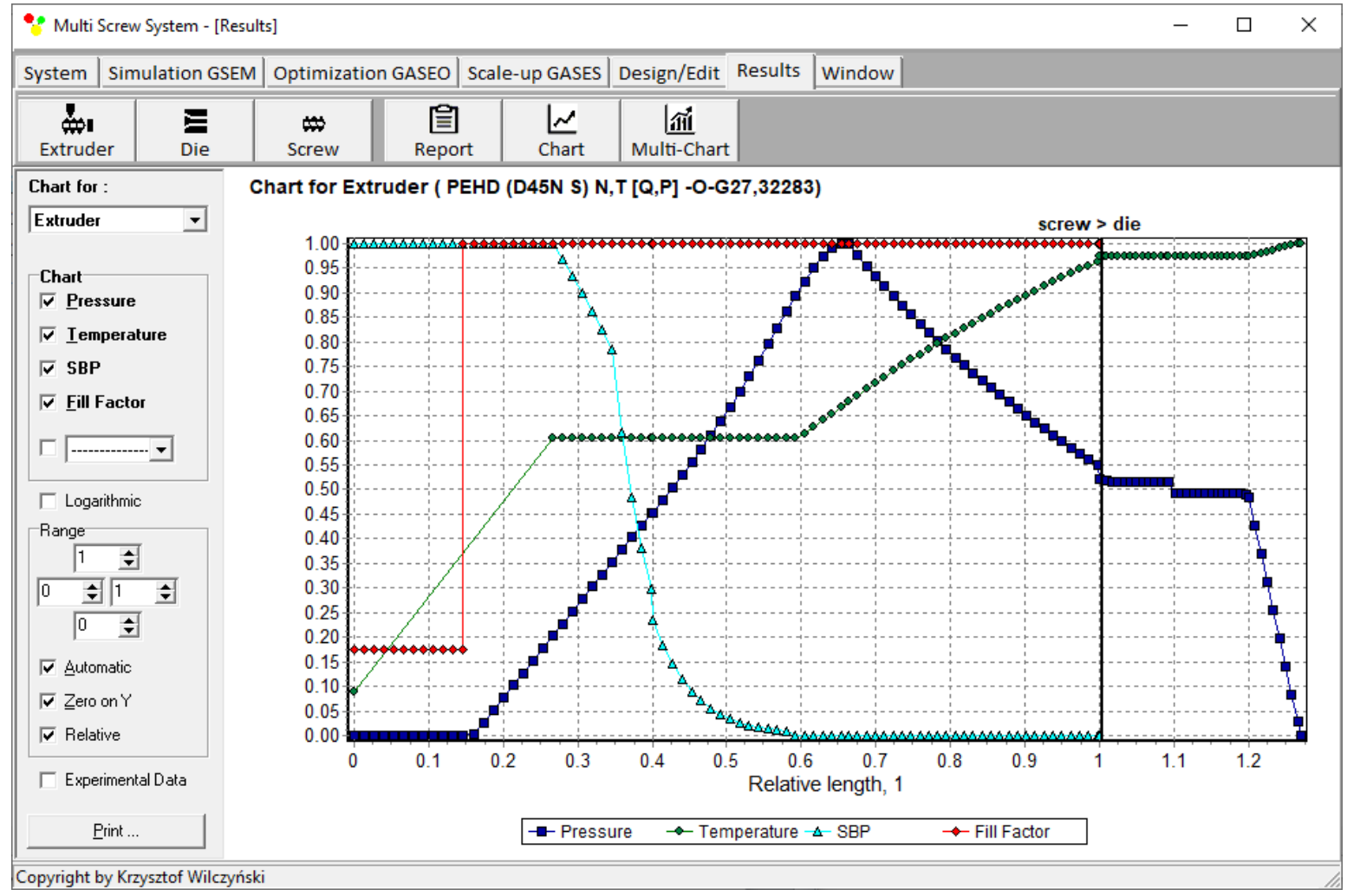

Figure 9. Extrusion with metered feeding: process characteristics (reference extruder) at optimal parameters.

With regard to such an optimized reference process, the extrusion scaling-up was performed in the same range of input data of the screw speed $N=20 \div 80 \mathrm{rpm}$, the barrel temperature in the subsequent sections of the extruder: $T_{1}=150{ }^{\circ} \mathrm{C}, T_{2}=150 \div 240{ }^{\circ} \mathrm{C}$, mboxemphT $_{3}=150 \div 240{ }^{\circ} \mathrm{C}, T_{4}=150 \div 240{ }^{\circ} \mathrm{C}$, and the feeding rate $Q_{\mathrm{ST}}=36 \div 42 \mathrm{~kg} / \mathrm{h}$.

Scaling-up was carried out according to the single-parameter criteria of the unit energy consumption $E_{S} S T$, the polymer melt temperature $T_{\text {melt }} S T$, and the relative "melting length" $L_{\text {melting }} S T$, i.e., the ratio of the screw length necessary for polymer melting to the screw length, and to the functional criteria of the temperature profile and the plasticating profile, i.e., the solid bed profile (SBP).

The global objective function was defined as,

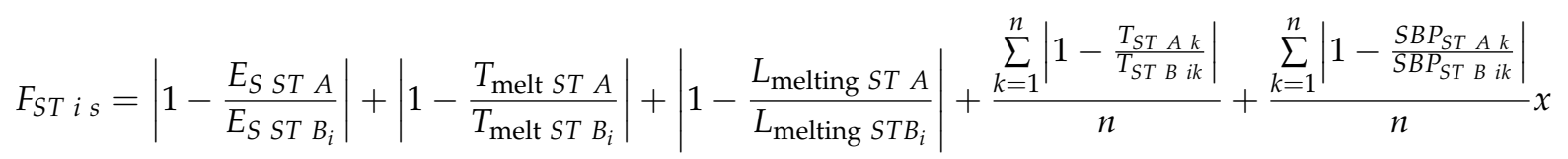

where $F_{S T \text { is }}$ is the global objective function for scale-up, $E_{\mathrm{S} S \mathrm{ST}}$ is the specific energy consumption for reference extruder, $E_{S} S T B i$ is the specific energy consumption for target extruder, $T_{\text {melt }}$ ST A is the melt temperature at die outlet for reference extruder, $T_{\text {melt }}$ ST Bi is the melt temperature at die outlet for target extruder, $L_{\text {melting }} S T$ A is the relative melting 
length for reference extruder, $L_{\text {melting }} S T B i$ is the relative melting length for target extruder, $T_{S T A}$ is the melt temperature in reference extruder, $T_{S T B i}$ is the melt temperature in target extruder, $S B P_{S T A}$ is the polymer melting profile for reference extruder, $S B P_{S T B i}$ is the polymer melting profile for target extruder, $i$ is a number of the next value from the data set, $n$ is a number of the next value in the profile.

The results of scaling-up are presented in Table 4, and Figures 10 and 11. The lowest value of the objective function (Equation (9)), i.e., the minimum discrepancy between the parameters of the reference and target process, was obtained at the screw speed $N=47.67 \mathrm{rpm}$ for the barrel temperatures: $T_{1}=150{ }^{\circ} \mathrm{C}, T_{2}=204{ }^{\circ} \mathrm{C}, T_{3}=194.33{ }^{\circ} \mathrm{C}, T_{4}=193{ }^{\circ} \mathrm{C}$, at the feeding rate $Q_{S T}=39.17 \mathrm{~kg} / \mathrm{h}$. These parameters correspond to the process output parameters of the unit energy consumption $E_{S} S T=360.32 \mathrm{~kJ} / \mathrm{kg}$, the polymer melt temperature $T_{\text {melt } S T}=200.67^{\circ} \mathrm{C}$, and the relative "melting length" $L_{\text {melting }} S T=0.571$. The differences between the parameters of the reference process and the target process are small (Table 4 ). Thus, it can be concluded that these processes are similar in terms of the selected criteria. The profiles of temperature and melting are also similar which is clearly presented in Table 4 and Figures 10 and 11. By increasing the scale of the process, a significant increase in the extrusion throughput was obtained (43.37\%).

Table 4. Results of scaling-up the starve fed extrusion process.

\begin{tabular}{|c|c|c|c|}
\hline \multicolumn{4}{|c|}{ Results of Scaling-Up the Extrusion Process } \\
\hline \multicolumn{4}{|c|}{ Extruder } \\
\hline Single Parameters & Reference & Target & Deviation \\
\hline Specific energy consumption & $453.84 \mathrm{~kJ} / \mathrm{kg}$ & $360.32 \mathrm{~kJ} / \mathrm{kg}$ & $20.61 \%$ \\
\hline Relative melting length & 0.617 & 0.571 & $7.46 \%$ \\
\hline Polymer melt temperature & $223.31^{\circ} \mathrm{C}$ & $200.67^{\circ} \mathrm{C}$ & $0.02 \%$ \\
\hline $\begin{array}{l}\text { Extrusion throughput/Feeding } \\
\text { flow rate }\end{array}$ & $27.32 \mathrm{~kg} / \mathrm{h}$ & $39.17 \mathrm{~kg} / \mathrm{h}$ & $43.37 \%$ \\
\hline \multicolumn{4}{|l|}{ Profiles } \\
\hline \multicolumn{4}{|l|}{ Temperature profile } \\
\hline 1. & $20.00^{\circ} \mathrm{C}$ & $20.00{ }^{\circ} \mathrm{C}$ & $0.00 \%$ \\
\hline 21. & $\begin{array}{c}\cdots \\
132.12{ }^{\circ} \mathrm{C}\end{array}$ & $\begin{array}{c}\cdots \\
135.00^{\circ} \mathrm{C}\end{array}$ & $\begin{array}{c}\cdots \\
2.18 \%\end{array}$ \\
\hline 22. & $135.00^{\circ} \mathrm{C}$ & $135.00^{\circ} \mathrm{C}$ & $0.00 \%$ \\
\hline $\begin{array}{c}\cdots \\
126 .\end{array}$ & $\begin{array}{c}\cdots \\
223.26^{\circ} \mathrm{C}\end{array}$ & $\begin{array}{c}\cdots \\
200.67^{\circ} \mathrm{C}\end{array}$ & $\begin{array}{c}\cdots \\
10.12 \%\end{array}$ \\
\hline \multicolumn{4}{|l|}{ SBP profile } \\
\hline 1. & 1.00 & 1.00 & $0.00 \%$ \\
\hline$\cdots$ & $\cdots$ & $\cdots$ & $\cdots$ \\
\hline 21. & 0.98 & 0.97 & $1.02 \%$ \\
\hline 22. & 0.95 & 0.94 & $1.05 \%$ \\
\hline 46. & $\begin{array}{c}\cdots \\
0.00\end{array}$ & $\begin{array}{c}\cdots \\
0.00\end{array}$ & $\begin{array}{l}\cdots \\
-\end{array}$ \\
\hline
\end{tabular}




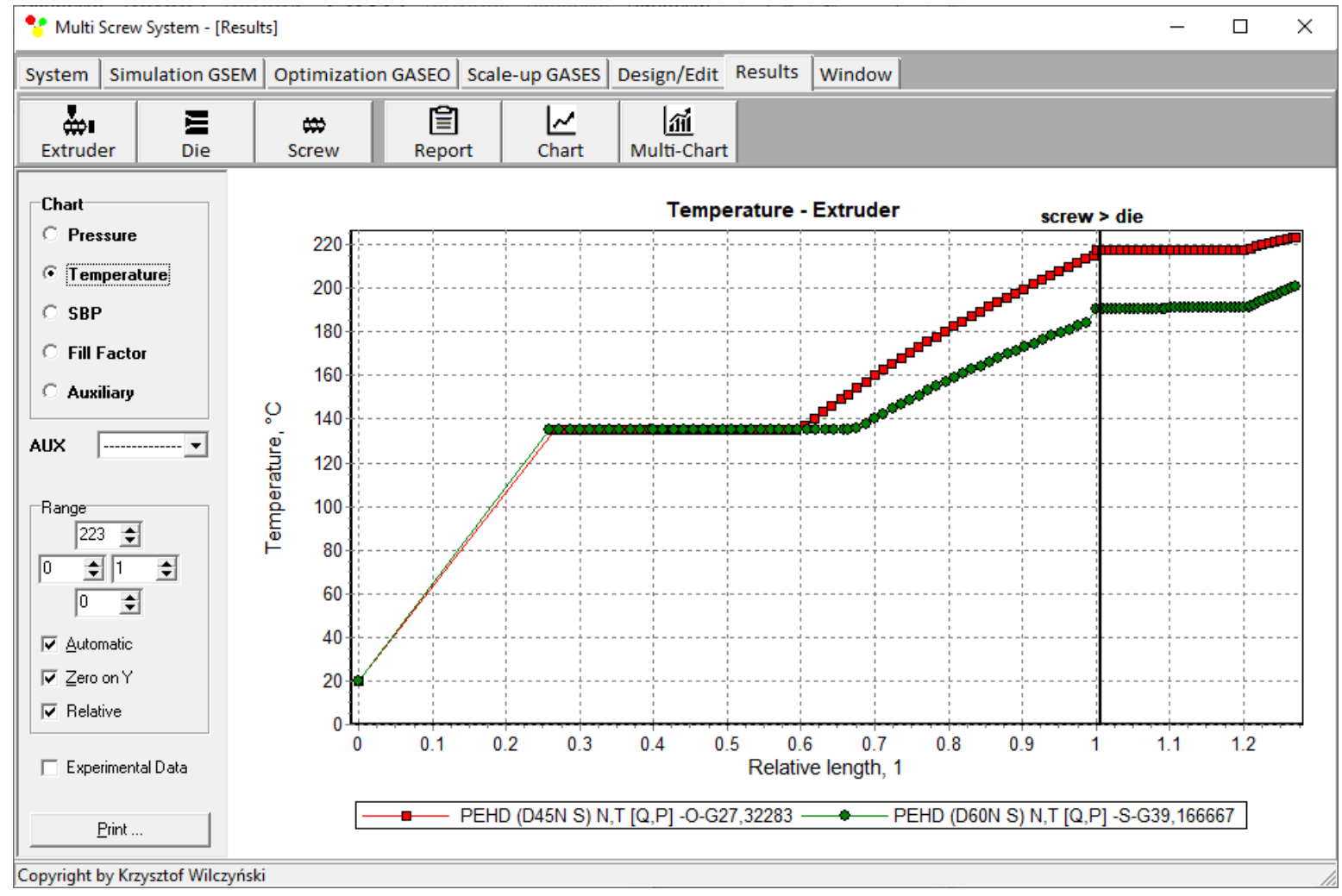

Figure 10. Starve fed extrusion: temperature profile for the reference (red line) and target (green line) extruder.

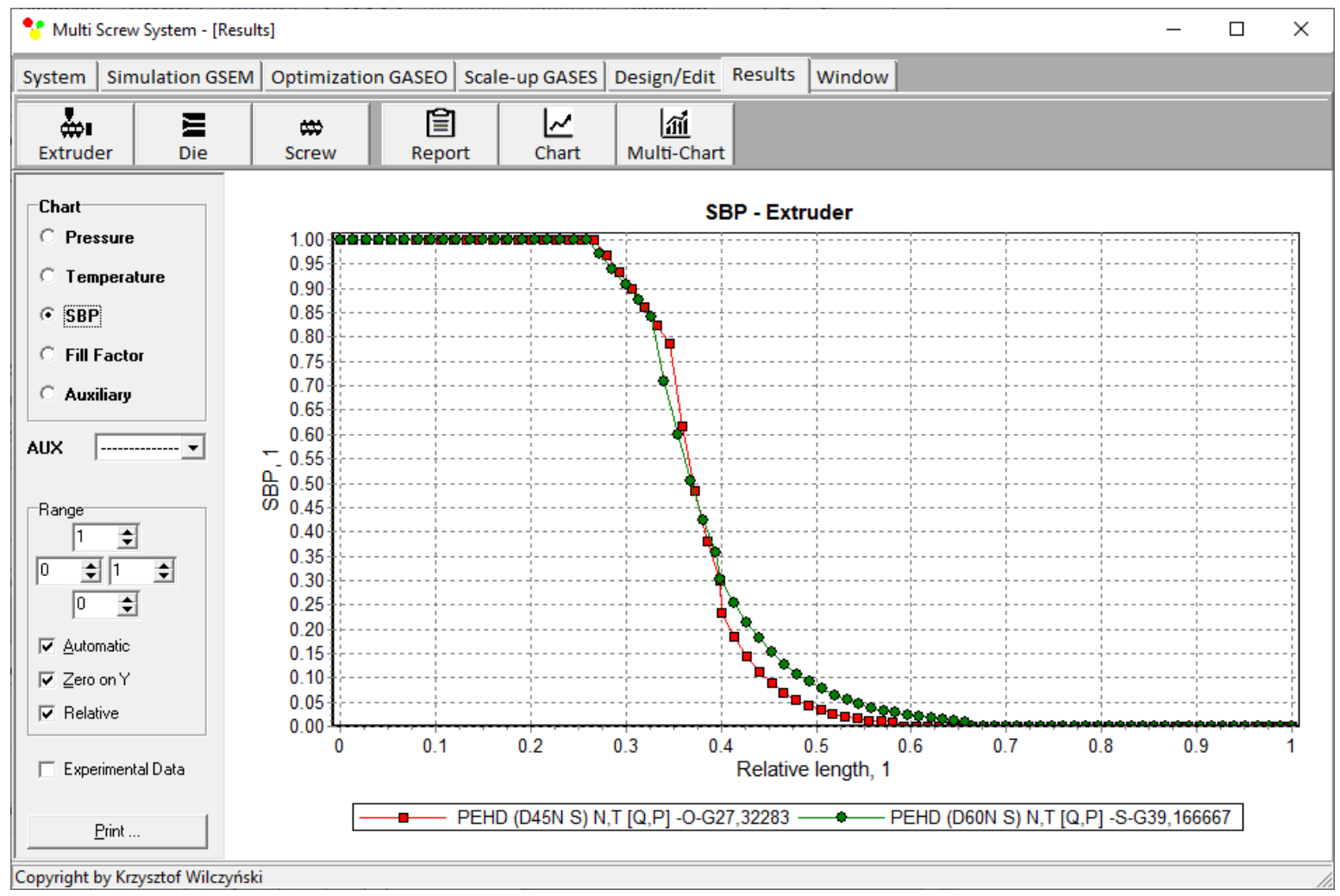

Figure 11. Starve fed extrusion: melting profile $(S B P)$ for the reference (red line) and target (green line) extruder. 


\section{Conclusions}

A novel scaling-up computer system for single screw extrusion of polymers has been developed. This system makes it possible to scale-up extrusion process with both starve feeding and flood feeding. Each of the scale-up criteria can be an objective function to be minimized, represented by single values or functional dependencies over the screw length. Scaling-up the extrusion process has been performed to increase extrusion output according to the scaling-up criteria defined by the single parameters of energy unit consumption, polymer melting rate, and polymer temperature, as well as by the process parameters profiles of temperature and melting. The global objective function reached the lowest value for the selected process parameters, and extrusion throughput was significantly increased. The use of functional scaling-up criteria in addition to the single-parameter criteria increased the accuracy of scaling-up.

It is worth noticing that the surface of the "roulette wheel" assigned to the individual genotypes is inversely proportional to the objective function values generated by these. When the genotype has the lowest value of the objective function, i.e., the highest value of the reciprocal of the objective function, the largest area of the "roulette wheel" is covered. When the genotype has the highest value of the objective function, i.e., the lowest value of the reciprocal of the objective function, the smallest area of the "roulette wheel" is covered.

So far, there is a lack of optimizing and scaling-up studies on the counter-rotating twin screw extrusion. However, the global models of this process are available. Thus, it seems to be reasonable to apply the Genetic Algorithms to solve this task, as for the co-rotating twin screw extrusion. Defining the screw geometry for the counter-rotating extrusion is similar to that for the co-rotating one, and differs from that for the single screw extrusion. In the former, the screw configuration is determined by choosing the screw elements from a set of elements available and locating them along the screw. In the latter, the geometry variables can vary continuously within a prescribed range.

Author Contributions: Conceptualization, A.N. and K.W.; methodology, A.N.; software, A.N.; validation, A.N.; investigation, A.N.; writing—original draft preparation, A.N.; writing-review and editing, K.W.; visualization, A.N.; supervision, K.W. All authors have read and agreed to the published version of the manuscript.

Funding: This research received no external funding.

Institutional Review Board Statement: Not applicable.

Informed Consent Statement: Not applicable.

Data Availability Statement: The data presented in this study are available on request from the corresponding author.

Conflicts of Interest: The authors declare no conflict of interest.

\section{References}

1. Mitchell, T.M. Machine Learning; McGraw-Hill Series in Computer Science; McGraw-Hill: New York, NY, USA, 1997; ISBN 9780070428072.

2. Antoniou, A.; Murray, W.; Wright, M.H. Practical Optimization: Algorithms and Engineering Applications; Springer: New York, NY, USA, 2007; ISBN 9780387711065.

3. Korte, B.; Vygen, J. Combinatorial Optimization; Algorithms and Combinatorics; Springer: Berlin/Heidelberg, Germany, 2012; Volume 21, ISBN 9783642244872

4. $\quad$ Ponce-Ortega, J.M.; Hernández-Pérez, L.G. Optimization of Process Flowsheets through Metaheuristic Techniques; Springer International Publishing: Cham, Switzerland, 2019; ISBN 9783319917214.

5. Bianchi, L.; Dorigo, M.; Gambardella, L.M.; Gutjahr, W.J. A Survey on Metaheuristics for Stochastic Combinatorial Optimization. Nat. Comput. 2009, 8, 239-287. [CrossRef]

6. Nesmachnow, S. An Overview of Metaheuristics: Accurate and Efficient Methods for Optimisation. Int. J. Metaheuristics 2014, 3, 320-347. [CrossRef]

7. Juan, A.A.; Faulin, J.; Grasman, S.E.; Rabe, M.; Figueira, G. A Review of Simheuristics: Extending Metaheuristics to Deal with Stochastic Combinatorial Optimization Problems. Oper. Res. Perspect. 2015, 2, 62-72. [CrossRef] 
8. Abdmouleh, Z.; Gastli, A.; Ben-Brahim, L.; Haouari, M.; Al-Emadi, N.A. Review of Optimization Techniques Applied for the Integration of Distributed Generation from Renewable Energy Sources. Renew. Energy 2017, 113, 266-280. [CrossRef]

9. Hussain, K.; Salleh, M.N.M.; Cheng, S.; Shi, Y. Metaheuristic Research: A Comprehensive Survey. Artif. Intell. Rev. 2019, 52, 2191-2233. [CrossRef]

10. Peres, F.; Castelli, M. Combinatorial optimization problems and metaheuristics: Review, challenges, design, and development. Appl. Sci. 2021, 11, 6449. [CrossRef]

11. Goldberg, D.E. Genetic Algorithms in Search, Optimization and Machine Learning; Addison-Wesley Longman Publishing Co.: Boston, MA, USA, 1989; ISBN 978-0-201-15767-3. [CrossRef]

12. Yang, X.-S. Nature-Inspired Optimization Algorithms, 1st ed.; Elsevier: Amsterdam, The Netherland; Boston, MA, USA, 2014; ISBN 9780124167438.

13. Fister, I., Jr.; Yang, X.-S.; Fister, I.; Brest, J.; Fister, D. A Brief Review of Nature-Inspired Algorithms for Optimization. arXiv 2013, arXiv:1307.4186.

14. Li, M.; Yang, S.; Liu, X. Pareto or Non-Pareto: Bi-Criterion Evolution in Multiobjective Optimization. IEEE Trans. Evol. Comput. 2016, 20, 645-665. [CrossRef]

15. Lones, M.A. Mitigating Metaphors: A Comprehensible Guide to Recent Nature-Inspired Algorithms. SN Comput. Sci. 2020, 1, 49. [CrossRef]

16. Covas, J.A.; Cunha, A.G.; Oliveira, P. An Optimization Approach to Practical Problems in Plasticating Single Screw Extrusion. Polym. Eng. Sci. 1999, 39, 443-456. [CrossRef]

17. Covas, J.A.; Gaspar-Cunha, A. The Use of an Optimization Approach to the Design of Extrusion Screw. In Proceedings of the Polymer Processing Society 16th Annual Meeting (PPS-16), Shanghai, China, 18-23 June 2000.

18. Gaspar-Cunha, A.; Covas, J.A. The Design of Extrusion Screw: An Optimization Approach. Int. Polym. Proc. 2001, 16, 229-240. [CrossRef]

19. Nastaj, A.; Wilczyński, K. Optimization for Single Screw Extrusion of Polymeric Materials—Experimental Studies. Polimery 2018, 1, 38-44. [CrossRef]

20. Nastaj, A.; Wilczyński, K. Process Optimization for Single Screw Extrusion of Polymeric Materials-Simulation Studies. Polimery 2018, 4, 297-304. [CrossRef]

21. Gaspar-Cunha, A.; Poulesquen, A.; Vergnes, B.; Covas, J.A. Optimization of Processing Conditions for Polymer Twin-Screw Extrusion. Int. Polym. Proc. 2002, 17, 201-213. [CrossRef]

22. Gaspar-Cunha, A.; Covas, J.A.; Vergnes, B. An Optimisation Methodology for Setting the Operating Conditions in TwinScrew Extrusion. In Materiaty Konferencyjne; The Polymer Processing Society Eighteenth Annual Meeting (PPS-18): Guimaraes, Portugalia, 2002.

23. Gaspar-Cunha, A.; Covas, J.; Vergnes, B. Defining the Configuration of Co-Rotating Twin-Screw Extruders with Multiobjective Evolutionary Algorithms. Polym. Eng. Sci. 2005, 45, 1159-1173. [CrossRef]

24. Nastaj, A. Optimization for Starve Fed Single Screw Extrusion of Polymeric Materials-Experimental Studies. Polimery 2020, 5, 380-386. [CrossRef]

25. Nastaj, A. Optimization for Starve Fed Single Screw Extrusion of Polymeric Materials—Simulations. Polimery 2020, 6, 468-477. [CrossRef]

26. Nastaj, A.; Wilczyński, K. Optimization for Starve Fed/Flood Fed Single Screw Extrusion of Polymeric Materials. Polymers 2020, 12, 149. [CrossRef] [PubMed]

27. Wilczyński, K.; Jiang, Q.; White, J.L. A Composite Model for Melting, Pressure and Fill Factor Profiles in a Metered Fed Closely Intermeshing Counter-Rotating Twin Screw Extruder. Int. Polym. Proc. 2007, 22, 198-203. [CrossRef]

28. Wilczyński, K.; Lewandowski, A.; Wilczyński, K.J. Experimental Study of Melting of LDPE/PS Polyblend in an Intermeshing Counter-Rotating Twin Screw Extruder. Polym. Eng. Sci. 2012, 52, 449-458. [CrossRef]

29. Lewandowski, A.; Wilczyński, K.J.; Nastaj, A.; Wilczyński, K. A Composite Model for an Intermeshing Counter-Rotating Twin-Screw Extruder and its Experimental Verification. Polym. Eng. Sci. 2015, 55, 2838-2848. [CrossRef]

30. Rauwendaal, C. Polymer Extrusion, 5th ed.; Carl Hanser Verlag: Munich, Germany, 2014; ISBN 978-1-56990-516-6.

31. Hensen, F.; Knappe, W.; Potente, H. Handbuch der Kunststoff-Extrusiontechnik. Grundlagen; Carl Hanser Verlag: Munich, Germany, 1989; ISBN 978-3446143395.

32. McKelvey, J.M. Polymer Processing; John Wiley \& Sons Inc.: New York, NY, USA, 1962; ISBN 978-0471584438.

33. Stevens, M.J.; Covas, J.A. Extruder Principles and Operation; Springer: Berlin/Heidelberg, Germany, 1995; ISBN 978-94-010-4247-5.

34. Campbell, G.A.; Spalding, M.A. Analyzing and Troubleshooting Single-Screw Extruders; Carl Hanser Verlag: Munich, Germany, 2013; ISBN 978-3-446-41371-9.

35. Chung, C.I. Extrusion of Polymers. Theory and Practice, 3rd ed.; Carl Hanser Verlag: Munich, Germany, 2019; ISBN 978-1-569-907375.

36. Chen, B.; Zhu, L.; Zhang, F.; Qiu, Y. Process Development and Scale-Up. In Developing Solid Oral Dosage Forms; Elsevier: Amsterdam, The Netherlands, 2017; pp. 821-868. [CrossRef]

37. Carley, J.F.; McKelvey, J.M. Extruder Scale-Up Theory and Experiments. Ind. Eng. Chem. 1953, 45, 989-992. [CrossRef]

38. Maddock, B.H. A Visual Analysis of Flow and Mixing in Extruder Screws. Soc. Plast. Eng. J. 1959, 15, $383-389$.

39. Maddock, B.H. Extruder Scale-up by Computer. Polym. Eng. Sci. 1974, 14, 853-858. [CrossRef] 
40. Fenner, R.T.; Williams, J.G. Some Melt Flow and Mechanical Design Aspects of Large Extruders. Polym. Eng. Sci. 1971, 11, 474-483. [CrossRef]

41. Yi, B.; Fenner, R.T. Scaling-up Plasticating Screw Extruders on the Basis of Similar Melting Performances. Plast. Rubber Process. 1976, 1, 119-123.

42. Pearson, J.R.A. Scale-up of Single Screw Extruders for Polymer Processing. Plast. Rubber Process. 1976, 1, $113-118$.

43. Potente, H.; Fischer, P. Model Laws for the Design of Single Screw Plasticating Extruders. Kunststoffe 1977, 67, $242-247$.

44. Schenkel, G. Extruder Series with Variable L/D Ratios. Kunststoffe 1978, 68, 155-162.

45. Chung, C.I. On the Scale-up of Plasticating Extruder Screws. Polym. Eng. Sci. 1984, 24, 626-632. [CrossRef]

46. Rauwendaal, C. Scale-up of Single Screw Extruders. Polym. Eng. Sci. 1987, 27, 1059-1068. [CrossRef]

47. Potente, H. Existing Scale-Up Rules for Single-Screw Plasticating Extruders. Int. Polym. Proc. 1991, 6, 267-278. [CrossRef]

48. Potente, H. Scale-up of Mixing Equipments. In Mixing and Compounding of Polymers, 2nd ed.; Manas-Zloczower, I., Ed.; Carl Hanser Verlag: Munich, Germany, 2009; pp. 577-643. ISBN 978-1-56990-660-6.

49. Covas, J.A.; Gaspar-Cunha, A. Extrusion Scale-up: An Optimization-based Methodology. Int. Polym. Proc. 2009, $24,67-82$. [CrossRef]

50. Berzin, F.; David, C.; Vergnes, B. Optimization and Scale-Up of Twin-Screw Reactive Extrusion: The Case of EVA Transesterification. Int. Polym. Proc. 2020, 35, 422-428. [CrossRef]

51. Covas, J.A.; Gaspar-Cunha, A. A Scaling-up Methodology for Co-rotating Twin-Extruders. In Proceedings of the 27th Annual Meeting of the Polymer Processing Society (PPS-27), Marrakesh, Morocco, 10-14 May 2011; pp. 1-6.

52. Gaspar-Cunha, A.; Covas, J.A. An Engineering Scale-Up Approach Using Multi-Objective Optimization. Intern. J. Nat. Comp. Res. 2014, 4, 17-30. [CrossRef]

53. Denysiuk, R.; Recio, G.; Covas, J.A.; Gaspar-Cunha, A. Using Multiobjective Optimization Algorithms and Decision Making Support to Solve Polymer Extrusion Problems. Polym. Eng. Sci. 2018, 58, 493-502. [CrossRef]

54. Nastaj, A. Scale-up for Single Screw Extrusion of Polymeric Materials. Polimery 2021, 6, 331-340. [CrossRef]

55. Nastaj, A.; Wilczyński, K. Optimization and Scale-Up for Polymer Extrusion. Polymers 2021, 13, 1547. [CrossRef]

56. Nastaj, A. Scale-Up for Starve Fed Single Screw Extrusion of Polymeric Materials. Polimery 2021, 9, 400. [CrossRef]

57. Wilczyński, K.J.; Nastaj, A.; Lewandowski, A.; Wilczyński, K. A Composite Model for Starve Fed Single Screw Extrusion of Thermoplastics. Polym. Eng. Sci. 2014, 54, 2362-2374. [CrossRef]

58. Wilczyński, K.J.; Lewandowski, A.; Nastaj, A.; Wilczyński, K. Modeling for Starve Fed/Flood Fed Mixing Single-Screw Extruders. Int. Polym. Proc. 2016, 31, 82-91. [CrossRef]

59. Wilczyński, K.J.; Lewandowski, A.; Nastaj, A.; Wilczyński, K. A Global Model for Starve-Fed Nonconventional Single-Screw Extrusion of Thermoplastics. Adv. Polym. Technol. 2017, 36, 23-35. [CrossRef]

60. Lopez-Latorre, L.; McKelvey, J.M. Melting and Pressurization in Starve Feed Extrusion. Adv. Polym. Technol. 1984, 3, 355-364. [CrossRef]

61. Isherwood, D.P.; Pieris, R.N.; Kassatly, J. The Effect of Metered Starve Feeding on the Performance of a Small Extruder. J. Eng. Ind. 1984, 106, 132-136. [CrossRef]

62. Strand, S.R.; Spalding, M.A.; Hyun, S.K. Modeling of the Solids-Conveying Section of a Starve Fed Single Screw Plasticating Extruder. SPE ANTEC Technol. Pap. 1992, 38, 2537-2541.

63. Gale, M. Compounding with Single-Screw Extruders. Adv. Polym. Technol. 1997, 16, 251-262. [CrossRef]

64. Thompson, M.R.; Donoian, G.; Christiano, J.P. Melting Mechanism of a Starved-Fed Single-Screw Extruder for Calcium Carbonate Filled Polyethylene. Polym. Eng. Sci. 2000, 40, 2014-2026. [CrossRef]

65. Rathner, R.; Tranchida, D.; Roland, W.; Ruemer, F.; Buchmann, K.; Amsüss, P.; Steinbichler, G. Properties of Starve-Fed Extrusion on a Material Containing a VHMWPE Fraction. Polymers 2021, 13, 944. [CrossRef]

66. White, J.L.; Potente, H. Screw Extrusion. Science and Technology; Hanser Publishers: Munich, Germany, 2003; ISBN 978-3-446-19624-7.

67. Tadmor, Z.; Gogos, C.G. Principles of Polymer Processing, 2nd ed.; John Wiley \& Sons Inc.: New York, NY, USA, 2006; ISBN 978-0-471-38770-1.

68. Osswald, T.; Hernandez-Ortiz, J.P. Polymer Processing. Modeling and Simulation; Carl Hanser Verlag: Munich, Germany, 2006; ISBN 978-3-446-40381-9.

69. Agassant, J.F.; Avenas, P.; Carreau, P.J.; Vergnes, B.; Vincent, M. Polymer Processing. Principles and Modelling, 2nd ed.; Carl Hanser Verlag: Munich, Germany, 2017; ISBN 978-1-56990-605-7.

70. Altinkaynak, A.; Gupta, M.; Spalding, M.A.; Crabtree, S.L. Melting in a Single Screw Extruder: Experiments and 3D Finite Element Simulations. Int. Polym. Proc. 2011, 26, 182-196. [CrossRef]

71. Ariffin, A.; Ahmad, M.S.B. Review: Single Screw Extruder in Particulate Filler Composite. Polym. Plast. Technol. 2011, 50, $395-403$. [CrossRef]

72. Teixeira, C.; Gaspar-Cunha, A.; Covas, J.A. Flow and Heat Transfer Along the Length of a Co-Rotating Twin Screw Extruder. Polym. Plast. Technol. 2012, 51, 1567-1577. [CrossRef]

73. Wilczyński, K.; Nastaj, A.; Lewandowski, A.; Wilczyński, K.J. Multipurpose Computer Model for Screw Processing of Plastics. Polym. Plast. Technol. 2012, 51, 626-633. [CrossRef] 
74. Malik, M.; Kalyon, D.M.; Golba, J.C., Jr. Simulation of Co-Rotating Twin Screw Extrusion Process Subject to Pressure-Dependent Wall Slip at Barrel and Screw Surfaces: 3D FEM Analysis for Combinations of Forward- and Reverse-Conveying Screw Elements. Int. Polym. Proc. 2014, 29, 51-62. [CrossRef]

75. Hyvärinen, M.; Jabeen, R.; Kärki, T. The Modeling of Extrusion Processes for Polymers-A Review. Polymers 2020, $12,1306$. [CrossRef] [PubMed]

76. Wilczyński, K.; Nastaj, A.; Lewandowski, A.; Wilczyński, K.J.; Buziak, K. Fundamentals of Global Modeling for Polymer Extrusion. Polymers 2019, 11, 2106. [CrossRef]

77. Wilczyński, K.; Lewandowski, A.; Wilczyński, K.J. Experimental Study for Starve-Fed Single Screw Extrusion of Thermoplastics. Polym. Eng. Sci. 2012, 52, 1258-1270. [CrossRef]

78. Wilczyński, K.; Nastaj, A.; Wilczyński, K.J. Melting Model for Starve Fed Single Screw Extrusion of Thermoplastics. Int. Polym. Proc. 2013, 28, 34-42. [CrossRef]

79. Wilczyński, K.; Nastaj, A.; Lewandowski, A.; Wilczyński, K.J.; Buziak, K. Experimental Study for Extrusion of Polypropylene/Wood Flour Composites. Int. Polym. Proc. 2015, 30, 113-120. [CrossRef]

80. Wilczyński, K.J.; Lewandowski, A.; Wilczyński, K. Experimental Study of Melting of Polymer Blends in a Starve Fed Single Screw Extruder. Polym. Eng. Sci. 2016, 56, 1349-1356. [CrossRef]

81. Wilczyński, K.; Buziak, K.; Wilczyński, K.J.; Lewandowski, A.; Nastaj, A. Computer Modeling for Single-Screw Extrusion of Wood-Plastic Composites. Polymers 2018, 10, 295. [CrossRef]

82. Wilczyński, K.J.; Nastaj, A.; Wilczyński, K. A Computer Model for Starve-Fed Single-Screw Extrusion of Polymer Blends. Adv. Polym. Technol. 2018, 37, 2142-2151. [CrossRef]

83. Mazzanti, V.; Mollica, F. A Review of Wood Polymer Composites Rheology and Its Implications for Processing. Polymers 2020, 12, 2304. [CrossRef]

84. Agur, E.E.; Vlachopoulos, J. Numerical Simulation of a Single-Screw Plasticating Extruder. Polym. Eng. Sci. 1982, 22, 1084-1094. [CrossRef]

85. Potente, H.; Hanhart, W.; Reski, T. Design and Processing Optimization of Extruder Screws. Polym. Eng. Sci. 1994, 34, 937-945. [CrossRef]

86. Wilczyński, K. Single Screw Extrusion Model for Plasticating Extruders. Polym.-Plast. Technol. 1999, 38, 581-608. [CrossRef]

87. Bawiskar, S.; White, J.L. A Composite Model for Solid Conveying, Melting, Pressure and Fill Factor Profiles in Modular Co-Rotating Twin Screw Extruders. Int. Polym. Proc. 1997, 12, 331-340. [CrossRef]

88. White, J.L.; Kim, B.-J.; Bawiskar, S.; Keum, J.M. Development of a Global Computer Software for Modular Self-Wiping Corotating Twin Screw Extruders. Polym.-Plast. Technol. 2001, 40, 385-405. [CrossRef]

89. Potente, H.; Bastian, M.; Flecke, J. Design of a Compounding Extruder by Means of the SIGMA Simulation Software. Adv. Polym. Technol. 1999, 18, 147-170. [CrossRef]

90. Vergnes, B.; Valle, G.D.; Delamare, L. A Global Computer Software for Polymer Flows in Corotating Twin Screw Extruders. Polym. Eng. Sci. 1998, 38, 1781-1792. [CrossRef]

91. Wilczyński, K. Rheology in Polymer Processing. Modeling and Simulation; Carl Hanser Verlag: Munich, Germany, 2021; ISBN 978-1-56990-660-6. 